\title{
Bridge-Induced Translocation between NUP145 and TOP2 Yeast Genes Models the Genetic Fusion between the Human Orthologs Associated With Acute Myeloid Leukemia
}

\author{
Valentina Tosato ${ }^{1,2,3 *}$, Nicole West ${ }^{4}$, Jan Zrimec ${ }^{2}$, Dmitri V. Nikitin ${ }^{5}$, Giannino Del Sal ${ }^{6}$, \\ Roberto Marano ${ }^{6}$, Michael Breitenbach ${ }^{7}$ and Carlo V. Bruschi ${ }^{3,7}$ \\ ${ }^{1}$ Ulisse Biomed S.r.l., AREA Science Park, Trieste, Italy, ${ }^{2}$ Faculty of Health Sciences, University of Primorska, Izola, Slovenia, \\ ${ }^{3}$ Yeast Molecular Genetics, ICGEB, AREA Science Park, Trieste, Italy, ${ }^{4}$ Clinical Pathology, Hospital Maggiore, Trieste, Italy, \\ ${ }^{5}$ Biology Faculty, M.V. Lomonosov Moscow State University, Moscow, Russia, ${ }^{6}$ Department of Life Sciences, University of \\ Trieste, Trieste, Italy, ${ }^{7}$ Genetics Division, Department of Cell Biology, University of Salzburg, Salzburg, Austria
}

\section{OPEN ACCESS}

Edited by:

Bernd Kaina,

Johannes Gutenberg-Universität

Mainz, Germany

Reviewed by:

Takaomi Sanda,

National University of Singapore,

Singapore

Gavin P. McStay,

New York Institute of Technology,

United States

*Correspondence:

Valentina Tosato

v.tosato@ulissebiomed.com

Specialty section:

This article was submitted to Molecular and Cellular Oncology,

a section of the journal

Frontiers in Oncology

Received: 15 June 2017 Accepted: 07 September 2017 Published: 29 September 2017

Citation:

Tosato V, West N, Zrimec J, Nikitin DV, Del Sal G, Marano R,

Breitenbach $M$ and Bruschi CV (2017) Bridge-Induced Translocation between NUP145 and TOP2 Yeast Genes Models the Genetic

Fusion between the Human Orthologs Associated With Acute Myeloid Leukemia.

Front. Oncol. 7:231.

doi: 10.3389/fonc.2017.00231
In mammalian organisms liquid tumors such as acute myeloid leukemia (AML) are related to spontaneous chromosomal translocations ensuing in gene fusions. We previously developed a system named bridge-induced translocation (BIT) that allows linking together two different chromosomes exploiting the strong endogenous homologous recombination system of the yeast Saccharomyces cerevisiae. The BIT system generates a heterogeneous population of cells with different aneuploidies and severe aberrant phenotypes reminiscent of a cancerogenic transformation. In this work, thanks to a complex pop-out methodology of the marker used for the selection of translocants, we succeeded by BIT technology to precisely reproduce in yeast the peculiar chromosome translocation that has been associated with AML, characterized by the fusion between the human genes NUP98 and TOP2B. To shed light on the origin of the DNA fragility within NUP98, an extensive analysis of the curvature, bending, thermostability, and B-Z transition aptitude of the breakpoint region of NUP98 and of its yeast ortholog NUP145 has been performed. On this basis, a DNA cassette carrying homologous tails to the two genes was amplified by PCR and allowed the targeted fusion between NUP145 and TOP2, leading to reproduce the chimeric transcript in a diploid strain of $S$. cerevisiae. The resulting translocated yeast obtained through BIT appears characterized by abnormal spherical bodies of nearly $500 \mathrm{~nm}$ of diameter, absence of external membrane and defined cytoplasmic localization. Since Nup98 is a well-known regulator of the post-transcriptional modification of P53 target genes, and P53 mutations are occasionally reported in AML, this translocant yeast strain can be used as a model to test the constitutive expression of human P53. Although the abnormal phenotype of the translocant yeast was never rescued by its expression, an exogenous P53 was recognized to confer increased vitality to the translocants, in spite of its usual and well-documented toxicity to wild-type yeast strains. These results obtained in yeast could provide new grounds for the interpretation of past observations made in leukemic patients indicating a possible involvement of $P 53$ in cell transformation toward AML.

Keywords: acute myeloid leukemia, bridge-induced translocation, gene fusion, yeast, nucleoporin, P53 


\section{INTRODUCTION}

Nucleoporins have important roles in many cellular pathways such as the nucleocytoplasmic transport (1), mitotic spindle assembly checkpoint (2), and chromatin metabolism (3). The sporadic rearrangement of their encoding genes lead to aberrant chimeric proteins often implicated in hematologic malignancies such as the acute myeloid leukemia (AML) (4). In particular, the amino terminus of Nup98 is known to be involved in the fusions with at least 28 different partners provoking different types of leukemia (5). In the past, several mouse models of retroviral-introduced artificial fusions have been developed $(6,7)$ and potential therapeutic targets for specific Nup98 fusions-mediated transformation are under studies (8), but the exact role of the Nup98 chimeras in cell immortalization remains still unclear $(9,10)$. Moreover, previous works were mostly focused on the clinical effects of the chimeric fusion rather than on the genetic etiology of the disease. We, therefore, planned an experiment to verify whether a chromosomal translocation involving NUP98 might be reproduced in a model organism such as Saccharomyces cerevisiae using our previously published bridge-induced translocation (BIT) system $(11,12)$. Among all the different possible chimeras leading to hematopoietic malignancies, we focused on a peptide resulting from the fusion between the genes NUP98 and TOP2B that had been found in a patient with primary AML (13). The choice of these two loci required a substantial long period of time and was dictated (i) by the necessity of a detailed sequence description of a translocation breakpoint in human cells, (ii) by the fact that these two genes (NUP98 and TOP2B) have orthologs in yeast and, (iii) by the topological orientation of these orthologs allowing the formation of a viable translocated yeast cell. The patient described in this paper (13) achieved complete histologic remission but relapsed 15 months after diagnosis and showed a 90\% blast cell infiltration in the bone marrow. The blast cells were resistant to a combination of Ara-C and topotecan, usually efficient in cases without a complete response (14), with a negative outcome (13). In this work, the precise DNA junction between the two genes had been clearly described, providing partial sequences of the NUP98/ TOP2B fusion. The breakpoint within NUP98 (Chromosome 11) occurred at nucleotide 1,199 of the intron 13 with a consequent deletion of two base pairs, while the breakpoint of TOP2B (Chromosome 3) occurred within nucleotide 687 within intron 25 , with a duplication of four base pairs (13). An important point is that at least two different reciprocal chimeric transcripts (TOP2B-NUP98) were identified, suggesting that a precise reciprocal construct is not essential for the leukemic transformation process. This observation is confirmed by other analyses of NUP98 fusions, where the reciprocal transcript was never found in leukemic patients $(15,16)$. Since BIT produces always non-reciprocal chromosome translocations $(17,18)$, the demonstration that the reciprocal transcript(s) did not play a role in the oncogenic

Abbreviations: BIT, bridge-induced translocation; AML, acute myeloid leukemia; HRS, homologous recombination system; 5-FOA, 5-fluoroorotic acid; TEM, transmission electron microscopy; TNT, translocant NUP-TOP; NPC, nuclear pore complex; TIDD, thermally induced duplex destabilization; SB, spherical body. transformation reinforced the idea to use BIT in the modeling of this particular translocation. BIT allows to precisely link together through a linear DNA cassette two targeted loci on different chromosomes, exploiting the Rad52/Rad54-dependent endogenous homologous recombination system (HRS) of the yeast cell (11, 18). The efficiency of the resulting translocation event depends on the length of the homologous ends, on the selected yeast strain and on the DNA stability of the targeted loci (19). Using BIT followed by a pioneering pop-out technology we succeeded to generate an in vivo perfect fusion between the genes NUP145 (ortholog to human NUP98) and TOP2 (ortholog to human TOP2B). Extensive conformational and physicochemical analyses of the DNA region around the breakpoints detected similarities and differences between yeast and mammalian DNA and enlightened the basis of the DNA weakness of NUP98. BIT produced a peculiar NUP-TOP translocated yeast strain (TNT), suggestively resembling a "leukemic yeast," which can be easily manipulated to investigate the genetic origin of the leukemic translocation process and the molecular players involved. Aged TNT cells are phenotypically characterized by huge, abnormal, spherical bodies (SBs), which can be stained by the RNA-intercalator Pyronin Y (PY). Differently from other types of tumors, P53 is rarely mutated in hematological malignancies while it is vice versa recurrently overexpressed (20-22). After constitutive expression of human P53 in TNT, in spite of the lack of a phenotypic reversion, an increased vitality and vigorous growth were observed. These data were completely unexpected since constitutively expressed P53 was found to be toxic in the parental wild-type (WT) yeast strain, in agreement with previous observations (23). Therefore, these results obtained in the model translocant yeast indicate that the human P53 is an energy booster for aneuploid yeast cells and, corroborating previous clinical data, suggest that P53 might be an indicator of cell transformation to $\operatorname{AML}(24,25)$ and its presence predictive of adverse prognosis (22). Moreover, we propose that the unusual phenotype of aged TNTs, characterized by huge RNArich SBs, could be related to the translocation involving Nup145. Further insights on the role of this nucleoporin in the function, size, and integrity of cytoplasmatic bodies are currently under investigation.

\section{MATERIALS AND METHODS}

\section{Strains and Media}

The diploid strain San1, constructed in our laboratory $(11,26)$ by mating Fas 20 ( $\alpha$, ade1 ade2 ade8 can1R leu2 trp1, ura3-52) (26) and YPH250 (a, ade2-101 ${ }^{\circ}$ leu2- $\Delta 1$ lys2-801a his3- $\Delta 200 \operatorname{trp} 1-\Delta 1$ ura3-52, ATCC 96519), was used to obtain the TNTs and as control strain throughout this work. To plot the growth curves, the cells were counted every $2 \mathrm{~h}$ and the values expressed in $10^{7}$ cells/ $\mathrm{ml}$. Each value is the result of three independent readings and its error bar is reported accordingly.

Yeast peptone dextrose (YPD), supplemented with geneticin (G418, final conc. $200 \mu \mathrm{g} / \mathrm{ml}$, Gibco), and Synthetic Complete (SC) - URA were used as selective media. To select for the TNTs, the SE drop-out-medium (with ammonium glutamate instead of ammonium sulfate) was prepared as previously described (27). 
5-Fluoroorotic acid (5-FOA) plates were prepared optimizing the protocol from Akada (28) with an increased amount of 5-FOA up to $1.2 \mathrm{~g} / \mathrm{l}$ and a decreased amount of uracil (final concentration $\leq 20 \mathrm{mg} / \mathrm{l}$ ) to minimize background.

\section{Translocants Construction and Analysis}

Plasmid pFA6aKlura (29) was used to amplify the gene URA3 from Kluyveromyces lactis (KIURA). while the plasmid pFA6aKANMX4 (30) was used as template to amplify the kanamycin gene. URA prototroph and G418-resistant transformants were obtained using the lithium-acetate transformation for the PCR-based gene replacement method (30). To obtain different constructs we prepared a template with 320 bp of NUP145 that were cut PstI/BamHI and cloned upstream the KlURA gene on the pFA6aKlura plasmid while 150 bp of NUP145 were cut SacI/EcoRI and cloned downstream the same plasmid as shown in Figure S1D in Supplementary Material. All the primers used to amplify the constructs and to verify them are listed in Table S1 in Supplementary Material. The constructs were all amplified by High-Fidelity PCR (Kapa Biosystems), purified and verified by sequencing (BMR sequencing service, Padova). The total amount of cells per transformation was $2.2 \times 10^{8}$ and the efficiency (E) of each transformation was determined dividing the frequency $(v)$ for the DNA amount in microgram used in the transformation process $(\nu / \mu \mathrm{g}$ DNA) (19).

Chromosome separation by contour-clamped homogeneous electric field (CHEF) and Southern hybridization were performed as previously reported (11) using probes amplified with primers listed in Table S1 in Supplementary Material. For the Gene Copy Number by quantitative PCR, the DNA was extracted using the Wizard Genomic DNA purification kit (Promega), then it was diluted from 10 to $50 \mathrm{ng} / \mu \mathrm{l}$ and quantified with a GeneQuant Pro spectrophotometer (NanoDrop1000, Thermo scientific) in order to define a standard curve, using as reference genes ACT1 on chromosome VI and SSE2 on chromosome II (31). Copy number of unknown samples was calculated from the standard curve by using the equation copy number $=10^{(\mathrm{Ct}-b) / m}$, where $b$ and $m$ represents $y$ intercept and slope, respectively.

The DNA copy number and the RT-PCR were run in a RotorGENE Q PCR (Qiagen) using the Rotor-Gene SYBR green KIT (Qiagen) and standard programs recommended by the supplier.

The data analysis of the RT-PCR was performed repeating the experiments at least three times and the relative gene expression (RGE) was calculated with the comparative C (T) method (32) using ACT1 as internal control gene and either the WT San1 or the translocant (both transformed with the empty pJL49) as reference strain to calculate the $\Delta \mathrm{C}(\mathrm{T})$ values.

\section{POP-OUT Selection of the Translocants and Stability Checking}

The translocants carrying the KlURA marker and labeled with the KAN gene on the translocated chromosome were grown for 2 days in non-selective medium and then overnight, from a fresh inoculum, in YPD + G418. The cells were plated on 5-FOA in serial dilutions from $3.2 \times 10^{7} /$ plate to $1 \times 10^{5} /$ plate using as positive control the auxotrophic strain San 1 and as negative control a prototrophic WT yeast strain. After replica plating to eliminate the background, the putative POP-OUT clones were re-streaked on SC-URA and on 5-FOA and verified by Southern blot, colony PCR, and genomic-PCR. In the case of a positive POP-OUT response (with consequent elimination of the marker), a DNA stretch (named "scar" because it was the result of homologous recombination even if it did not contain any exogenous DNA) of 659 bp was amplified with primers FwNUP and REVTOP (Table S1 in Supplementary Material) and sequenced. In all the figures, if not differently specified, the standard DNA ladder was always the $1 \mathrm{~kb}$ Plus (Invitrogen). Stability tests of the translocated chromosome were performed growing each TNT translocant in non-selective medium, plating $100 \mu \mathrm{l}$ of a $2 \times 10^{3} / \mathrm{ml}$ dilution on 40 YPD plates and replicating them on G418 after 2 days.

\section{Microscopy}

DAPI and FUN-1 staining (Molecular Probes, OR, USA) were performed as previously described (17) using a Leica DMBL photomicroscope equipped with a CCD computer-driven camera at $60 \times$ and $100 \times$ magnifications. The endocytosis assay was performed using the dye lucifer yellow (LY, Sigma; final conc. $4 \mathrm{mg} / \mathrm{ml}$ ) with an optimized Riezman protocol (33), as previously described (34), and detecting the fluorescence in the FITC channel. The PY (Sigma) staining on yeast cells was performed dissolving the powder in an acid solution (15\% acetic acid in water) and diluting it several times with water, reaching $1 \mu \mathrm{g} / \mathrm{ml}$ as optimal working concentration. The yeast cells were then centrifuged, washed twice with water (to eliminate the background generated by the medium), and resuspended in a maximum of $50-100 \mathrm{ng} / \mathrm{ml}$ PY solution. The amount of PY was never exceeded to avoid signal interference from the nuclear DNA, as also previously suggested at the FOM2011 Conference by Rybak (35). ${ }^{1}$ When cell wall visualization was needed, Calcofluor White M2R (final concentration $25 \mu \mathrm{M}$ ) was added to the yeast cell suspension already labeled with PY. After incubation at $30^{\circ} \mathrm{C}$ in the dark for few minutes, fluorescence was detected exciting PY and Calcofluor with green and UV light, respectively.

After 4 weeks of continuous growth, the morphology of TNTs was analyzed through transmission electron microscopy (TEM). The fixation step with glutaraldehyde was followed by a postfixation step with osmium tetroxide and by a dehydration step with increasing percentages of ethanol. Then the samples were embedded within the epoxy resin Derr 332-732. After a three-day resin polymerization, the samples were cut in 10-20 nm-thick sections with an ultramicrotome (Leica Ultracut UCT) equipped with a diamond blade (Drukker). Sections were thus laid down in a holder grid and incubated $10 \mathrm{~min}$ at room temperature with a $0.1 \%(\mathrm{w} / \mathrm{v})$ lead citrate solution and a $2 \%(\mathrm{w} / \mathrm{v})$ uranyl acetate solution; after each incubation, the grid was washed 20 times by immersion in water. Finally, samples were observed with a transmission electron microscope EM 208 (Philips) equipped with a Morada 4,008 $\times 2,672$ pixels 14 Bit-camera and an acquiring system Olympus Soft Imaging Solutions $\mathrm{GmbH}$.

\section{Bioinformatics}

Physicochemical and conformational properties of the DNA breaking strands were predicted with different models: (i) relative

${ }^{1}$ http://www.focusonmicroscopy.org/2011/PDF/412_Rybak.pdf. 
DNA duplex stability $(d G)$ with the thermodynamic nearestneighbor model and unified free energy parameters at $37^{\circ} \mathrm{C}(36)$; (ii) thermally induced duplex destabilization (TIDD) with the TIDD server ${ }^{2}$ (37) using the M5P model with 6 bp neighboring regions and a threshold of $0.1 \AA$; (iii) B-to- $\mathrm{A}(B A)$ and B-to-Z $(B Z)$ transitions according to the dinucleotide model parameters described in Lisser and Margalit (38); (iv) DNA bending, complexity, and curvature analysis were performed using the bend.it ${ }^{\circledR}$ server (39) with a curvature/complexity window size of 50-70 nt and a cubic spline smoothing. Sequence complexity, calculated according to the Shannon entropy or Kolmogorov methods, had been previously defined (40). Bending was considered as produced by a rolling of adjacent base pairs over one another about their long axes with the tilting of base pairs about their short axes that could make a contribution. By contrast, curvature was defined as relatively macroscopic DNA bend, representing the intrinsic tendency of DNA to follow a non-linear pathway over an appreciable length, which is a result of variation of local bends in phase with the DNA helix (41); (v) DNA persistence length ( $z$, proportional to bending rigidity) and DNA helical repeats ( $h$, number of bps per helix turn) with the model based on cyclization experiments of short DNA fragments (42). The structural properties were predicted in windows of $100 \mathrm{bp}$, except with TIDD, where $20 \mathrm{nt}$ was used, and the bending/curvature, where windows from 70 to $100 \mathrm{nt}$ were used. To build the control range, five known fragile sequences under ongoing spontaneous breaks (three from TEL1/ETV6, one from PML2, and one from the RARA gene) have been analyzed with the same programs.

Sequences aligning and comparisons were verified with the NCBI database using the specialized BLAST bl2seq. Functionally, conserved aminoacids (aa) were found and represented with the Seq2Logo programme exploiting the Kullback-Leibler logo type and the Hobohm 1 clustering method, correcting the displayed frequencies for low number of observations as described (43). Regulatory DNA motifs were identified running SCOPE 2.1.0 [Dartmouth College, NH, USA; (44)] on both DNA strands.

\section{RESULTS}

\section{Identification of the Translocation Breakpoint in Yeast}

In Homo sapiens (Hs) Nup98 is coded together with Nup96 by the same open reading frame and produced by autopeptidase cleavage. In S. cerevisae $(S c)$ the whole length of the protein is 1,317 amino acids-long and it is composed of 605 residues of $\mathrm{N}$-terminal Nup145 (ortholog to Nup98) and of 712 residues of C-terminal Nup145 (ortholog to Nup96). We found that the identity (BLASTp) between $H s$ Nup9 98 and ScNup 145 is on average 36\% with peaks of $72 \%$ within short regions while the identity between HsTop2B and ScTop2 is on average much higher (Figure 1A) since topoisomerases are well conserved, with structural insights from the yeast enzymes that are likely to apply to the human ones (45). The most conserved region (90\% positives) between Nup98 and Nup145 is represented by a hydrophobic stretch of 11

\footnotetext{
${ }^{2}$ http://tidd.immt.eu.
}

residues immediately before the breakpoint. Exploiting the good level of homology between yeast and human sequences, it was, therefore, easy to pinpoint the corresponding, virtual breakpoint in S. cerevisiae (Figure 1) and to design the primers (Table S1 in Supplementary Material) for a BIT cassette amplification that would model the chromosomal translocation etiology of the leukemic transformation in yeast (Figure 2).

\section{Construction of the Translocation "NUP-TOP" (TNT)}

To generate the translocation between nup and top loci, we implemented a methodology based on the following steps and briefly summarized in Figure 2: (a) amplification of a DNA cassette carrying the selection marker and two homologies toward nup145 (Chromosome VII) and top2 (Chromosome XIV) loci; (b) transformation of the yeast diploid strain San 1 and selection for the correct translocants on G418 plates; (c) POP-OUT of the marker and verification of the precise fusion of the two coding sequences. KIURA3, the orotidine-5'-phosphate decarboxylase gene from $K$. lactis, whose loss can be easy counter-selected on 5-FOA, was chosen as selective marker (see Materials and Methods for details). We planned to perform the POP-OUT of the marker exploiting the homologous recombination between direct repeats (Figure 2). Since the recombination frequency between 40 bp repeats in yeast vegetative cultures was calculated as $2.9 \times 10^{-6}$, with a 100 -fold variation range, probably due to the intrinsic property of the selected sequence (28), we decided to test a set of constructs differing among them for the length of the repeat (from 40 to $800 \mathrm{bp}$ ) and for the length of the homologous ends (from 40 to $100 \mathrm{bp}$, see Table S1 in Supplementary Material). When the short repeat (40 bp) and the standard length of homology of a BIT cassette $[65 \mathrm{bp}(11,19)]$ were used, the efficiency of the translocation NUP-TOP was very poor $(0.6 \%)$ while when the repeats were extended up to $800 \mathrm{bp}$, even single site integration (SSI) events were favored against BIT [data not shown; for a detailed description of the differences between BIT and SSI pathways see Ref. (46)]. The optimal length of the repeat was found to be around $150 \mathrm{bp}$ while the ideal length of the homologies for an efficient targeting was $100 \mathrm{bp}$. Using this optimized BIT cassette, we were able to find 6 clones, out of 177 screened, with both ends integrated in the corrected loci (Table S2 in Supplementary Material). Surprisingly, none of them gave rise to the amplification of the bridge either by colony or genomic PCR even using two different sets of primers chosen on the two chromosomes around the translocation breakpoint (Table S1 in Supplementary Material). Moreover, sequencing of the junctions showed point mutations and/or rearrangements in four out of these six clones and Southern blot hybridization revealed that only one of them (cl. 112) had the translocant of the expected size (Figure S1C in Supplementary Material). We assumed that, in the majority of clones, a faulty recombination had happened among different copies of the cassette inside the cell leading to an unwanted concatemer (Figure S1B in Supplementary Material). This hypothesis was verified by colony PCR with primers $\mathrm{k} 1$ and k2 (Figure S1B in Supplementary Material) and was confirmed by quantitative PCR analysis, which detected at least 10 copies of the cassette. The concatemer was also generated with short repeats 
A

\section{Nup145 (1317 aa)}

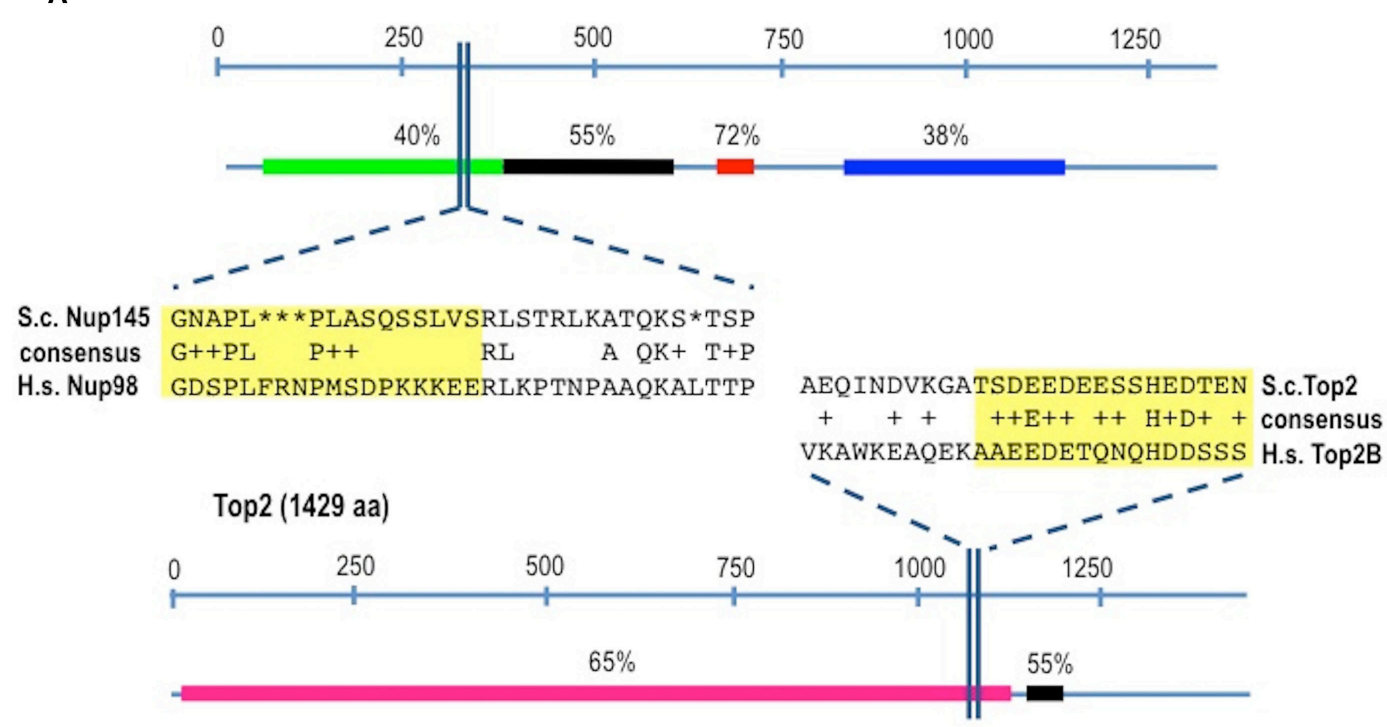

B
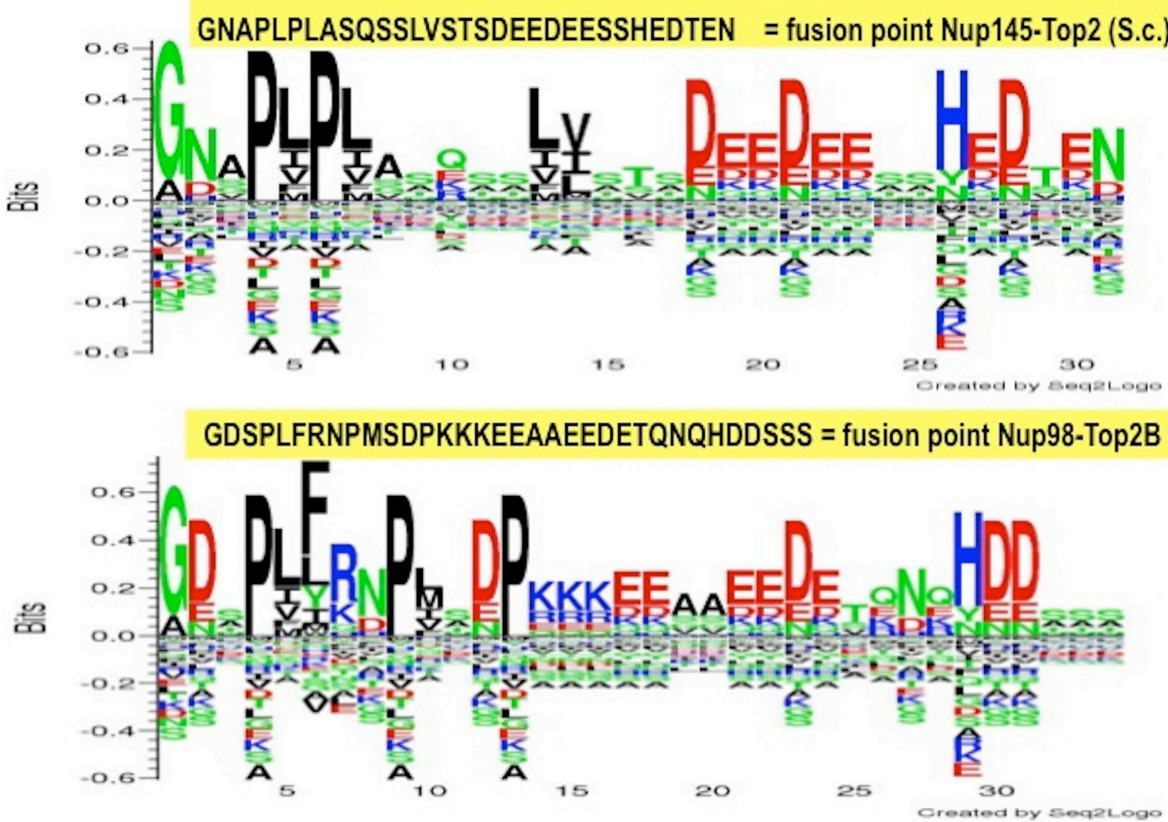

FIGURE 1 | Identification of the virtual breakpoints within the yeast proteins Nup145 and Top2 through an alignment with the human orthologs. (A) Breakpoints within the yeast proteins and their homology in percentages with the human orthologs (line below each protein) are shown. In the windows, a partial sequence alignment between yeast (S.c.) and human (H.s.) proteins and the relative consensus are presented. The parts of the proteins that are going to be fused together resulting in chimeras are outlined in yellow. aa, amino acids. (B) The fusion points in yeast (top panel) and in human (bottom panel) are represented by the Seq2Logo server. Large symbols represent frequently observed amino acids, big stack represents conserved positions and small stack represents variable positions. The $Y$-axis describes the amount of information in bits. The $X$-axis shows the position in the alignment.

of at least $40 \mathrm{bp}$ (data not shown). In order to reduce the length of the concatemer and to get the correct TNT, clone 112 was left growing in rich, non-selective medium for 1 week. Then it was diluted and plated on YPD, -URA, and 5-FOA medium. Among all the clones screened, one (cl.15) that was strongly flocculating, grew on YPD and on -URA, negligibly on 5-FOA, and had the expected size $(2,460 \mathrm{bp})$ of the correct bridge between nup145 and top 2 loci. This clone was verified by sequencing and Southern blot and it was subsequently used for the POP-OUT of the marker KlURA (Figure 2). 


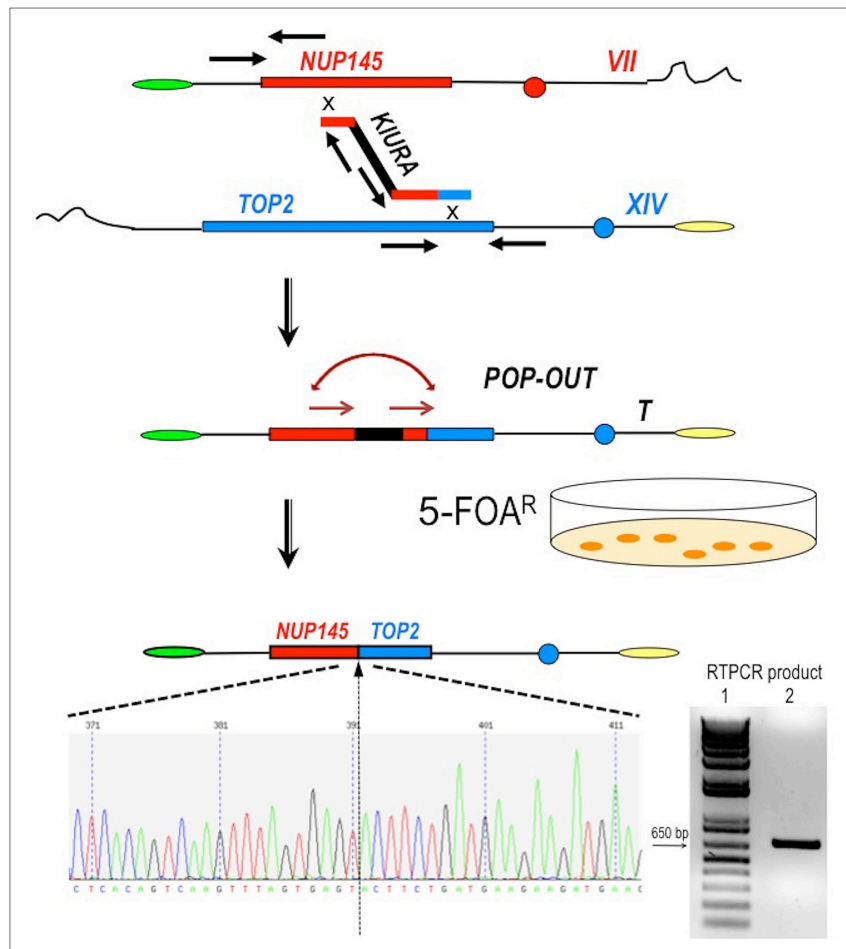

FIGURE 2 | Scheme of the procedure to obtain a perfect fusion between NUP145 and TOP2. The first step is represented by the bridge-induced translocation between NUP145 (Chromosome VII, shown in red) and TOP2 (Chromosome XIV, shown in blue) triggered by a BIT cassette. The URA3 gene from Kluyveromyces lactis (KIURA) was used as selection marker between the two homologous ends. Its POP-OUT, indicated by sequential arrows, was verified by selection on 5-FOA plates. The original chromatogram of one clone showing the perfect fusion between the two genes and the relative amplified chimeric transcript from one translocant (T) are also reported. Since the primers used in the RTPCR (sequence in Table $\mathrm{S} 1$ in Supplementary Material) are 418 and $241 \mathrm{bp}$ far from the junction point, respectively, the size of the amplicon shown here is exactly $659 \mathrm{bp}$ (lane 2 of the gel); lane 1:1 kb Plus ladder (Invitrogen).

Before the POP-OUT, the translocated chromosome of the TNT strain was labeled to avoid false positives on 5-FOA (clones that grow on 5-FOA because they have lost the whole translocated chromosome and not the KlURA marker only). We, therefore, introduced the KAN gene within the right arm of the translocated chromosome, between PHO91 and YNR014W (Figure S2 in Supplementary Material-for the primers sequence and their exact location see Table S1 in Supplementary Material).

The POP-OUT was performed as described in Section "Materials and Methods" and happened with an approximate frequency of $1 \times 10^{-6}$. The $659 \mathrm{bp}$-scar left by the KlURA gene was amplified with primers FwNUP and RevTOP (Table S1 and Figure S1 in Supplementary Material; Figure 2) and sequenced. The POP-OUT resulted in the wanted, perfect junction between chromosome VII (position 338787) and chromosome XIV (position 460959) (the partial sequence and chromatogram is reported in Figure 2). We repeated the procedure (KAN labeling, POP-OUT followed by replica and selection) three different times obtaining nine TNTs (Translocants "NUP-TOP"). All of them were analyzed in details.

\section{Characterization of the Translocants}

Translocants NUP-TOP were confirmed by DNA sequencing of the junction between chromosome VII and XIV and they were afterward analyzed by contour-clamped homogeneous electric field (CHEF) followed by Southern blot and sequential hybridizations (Figure S3 in Supplementary Material). Six out of nine translocants (clones 1, 2, 6, 7, 8, 10) showed a correct size of the translocated chromosome while three (clones 3, 4, 9) showed unexpected bands suggesting either spurious clones (as in clone 4) or abnormal rearrangements (for details, see the hybridizations panels of Figure S3 in Supplementary Material). The correct TNTs were further analyzed to check their phenotype while the expression of their chimeric transcript was verified by RT-PCR (Figure 2). The translocated chromosome was very stable also without selection, with $0.03 \%$ average of chromosome loss frequency in all the TNTs. Interestingly, when the translocants were left growing for at least 2 weeks, peculiar SBs started to mature within the cells. These structures have neither been found in other aged BIT yeast translocants (47) nor in human AML cells where only rod-shaped inclusions composed of fused lysosomes/primary neutrophilic granules, named Auer bodies, can be detected within the cytoplasm (48). DAPI (Figure 3A), and especially the RNA-specific dye PY (Figure 3B; Figure S4 in Supplementary Material), easily stained SBs, indicating an accumulation of RNA within the TNTs cells. The difference between the PY staining of the WT and of the translocants is remarkable (Figure S4 in Supplementary Material). To better investigate the SBs, a series of 4-week-old TNTs (Figure 3C) was observed in details by means of TEM. SBs appeared as big, interspersed cytoplasmic aggregates, lacking a surrounding membrane (Figure 4). The content of SBs is poorly electron dense, due probably to a progressive loss of material during the fixation procedure.

Spherical bodies are very different from stress granules as size, localization and number and are more similar to P-bodies (49) although they seem to condense into punctate patches (Figure 4).

\section{Genotypic and Phenotypic Investigation of the Translocation Loci}

NUP145 and TOP2 are both essential genes in budding yeast and NUP145 has been reported as haploinsufficient in rich medium (50). Synthetic lethality (BioGRID, Biological General Repository for Interaction Datasets) or genetic interactions (DRYGIN, Data Repository of Yeast Genetic Interactions) are not known between these two genes. Thus, to verify the phenotype of the NUP-TOP translocants in our genetic background, we performed the gene deletion of NUP145 and TOP2. While TOP2 deletion resulted, as expected, in a haploproficient phenotype (with approximately $90 \%$ of successful one-copy deletion), we confirmed that also in our genetic background NUP145 is not only essential (51) but also haploinsufficient (50) since the heterozygous full gene deletion was never achieved even extending the homologies (data not shown). However, we succeeded in the partial deletion of one copy of NUP145 with a frequency of $9.8 \%$. Performing this deletion (with primers FwNupKlura, RevNUP-KO-Klura; Table S1 in Supplementary Material), a fragment of $861 \mathrm{bp}$ at the $5^{\prime}$ 
A

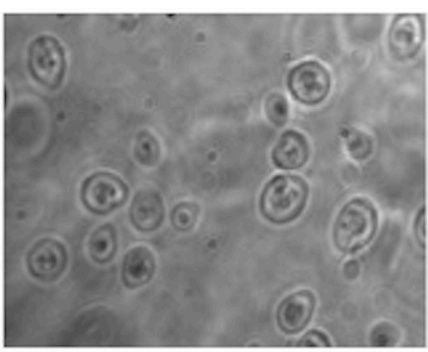

B

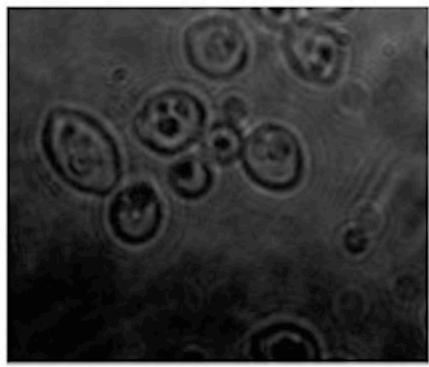

C

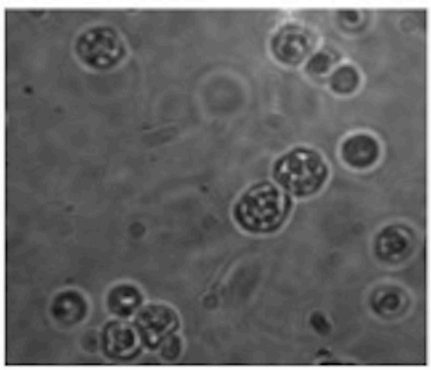

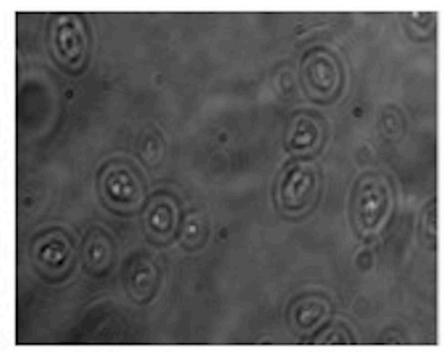
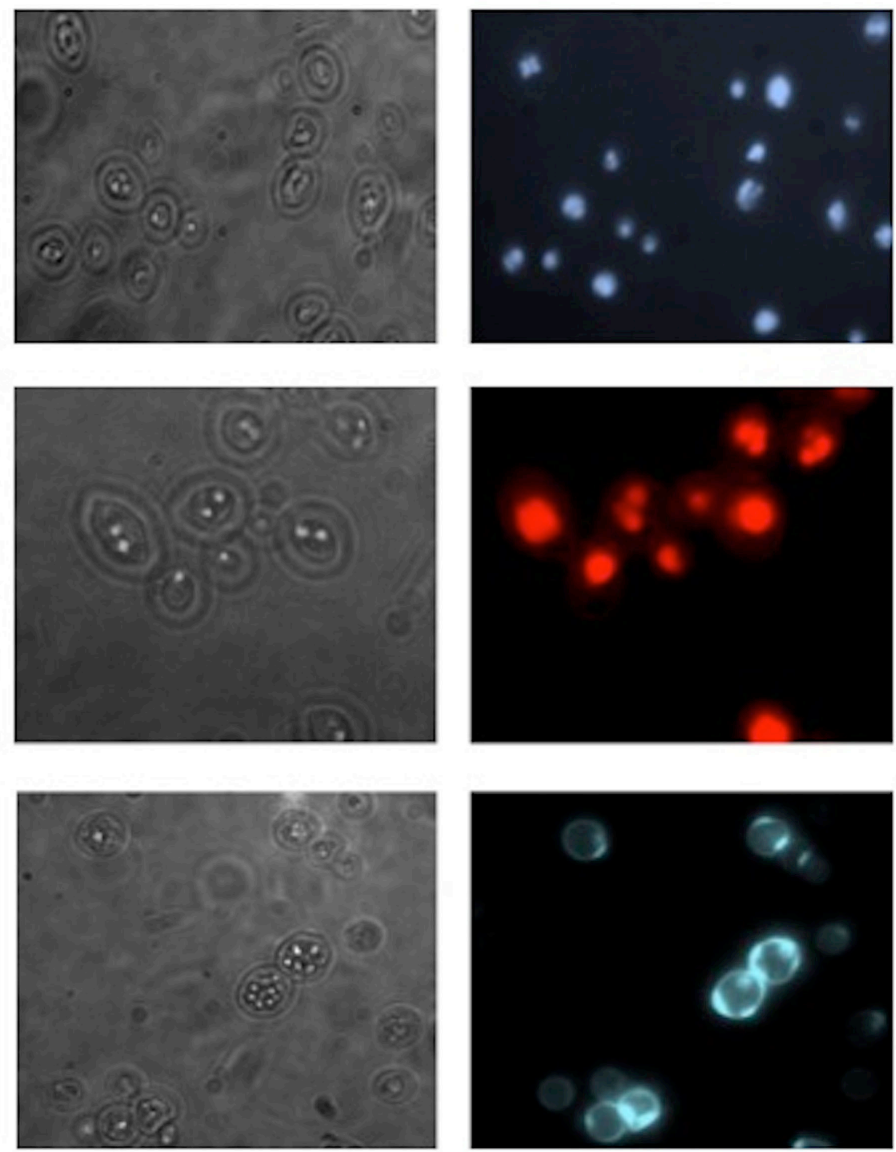

FIGURE 3 | Fluorescent microscopy of aged (3 weeks old) NUP-TOP translocants. The spherical bodies, whose number increased with aging, can be visualized also without fluorescence using different focus lengths (the first two pictures of each panel), but they become more evident after staining with DAPI (A) and Pyronin Y (B). After 4 weeks, all the cells of all the TNTs translocant strains contain a variable number of SBs. Cell aging is testified by the numerous scars on the cell wall that are visible after calcofluor treatment (C)

end was left in homozygous condition, exactly as in the TNTs, suggesting that this gene portion is sufficient to avoid haploinsufficiency in rich medium. These data support early observations $(52,53)$ proposing that $200 \mathrm{bp}$ at the $5^{\prime}$ end of NUP145 are necessary to avoid haploinsufficiency in minimal medium (SC-LEU). We concluded that the 287 aa haplosufficient $\mathrm{N}$-terminal region of Nup145, which contains also the GLFG (gly-leu-phe-gly) structural domain and which is part of the chimeric construct after the NUP-TOP translocation, is essential for diploid cells survival. Moreover, the overexpression of both NUP145 and TOP2 was verified in different background strains in the past (for a detailed description of the phenotypes and a list of references, see the Saccharomyces Genome Database at www.yeastgenome. org/), but the presence of the phenotype observed in TNTs was never reported.

To verify the possible influence of secondary structures on the fragility of the NUP98 sequences, we performed extensive bioinformatics analyses of the region around the breakpoints to identify putative motifs responsible for non-B DNA conformations.

\section{Bioinformatic Analysis of the Breakpoints}

The programme SCOPE-algorithm BEAM-(54) identified a direct, non-degenerate repeat $\left(5^{\prime}\right.$-ACTAGA- $\left.3^{\prime}\right)$ leading to a slipped (hairpin) structure exactly at the breakpoint, within intron 13 (Chr. 11) of NUP98 (Figure S5 in Supplementary Material). Running the same program with the algorithm SPACER it was possible to detect an inverted, degenerated repeat (5'-ACAAYRTTG-3') within the breakpoint of intron 25 (Chr. 3) of $T O P 2 B$ (data not shown). While the hairpin structure is responsible for non-B DNA, the degenerated inverted repeats are often found in rearrangement events in eukaryotes (55).

Since not only hairpins-prone repeats (56) but also repeated bending (57) can affect nicking at non-B DNA conformations and can, therefore, induce chromosomal translocations through nonhomologous end joining (58), or homologous recombination (59) we analyzed the curvature and bending of the DNA within the nup locus.

The bend.it analysis of NUP98 genomic DNA revealed high GC content and high bending immediately before and after the region of the intron 13 that spontaneously breaks (Figures 5A-C). A 


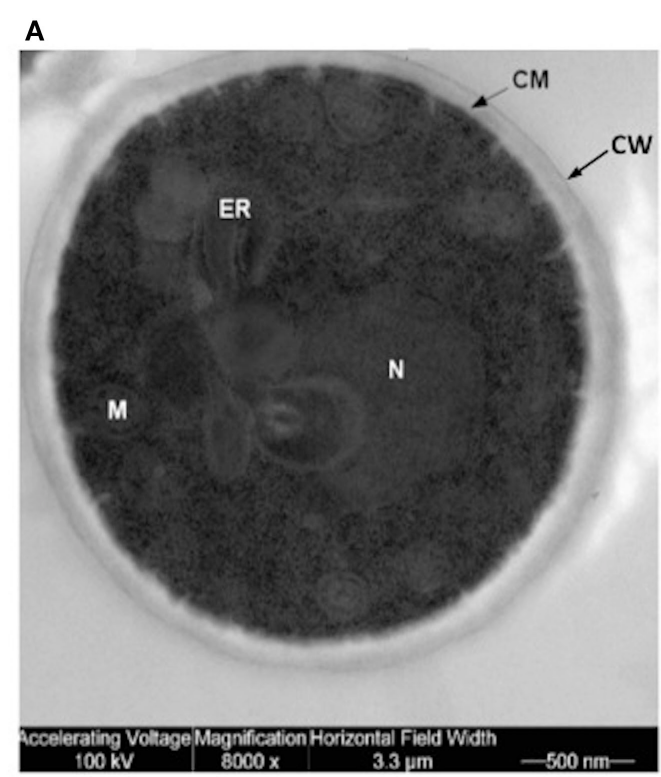

C

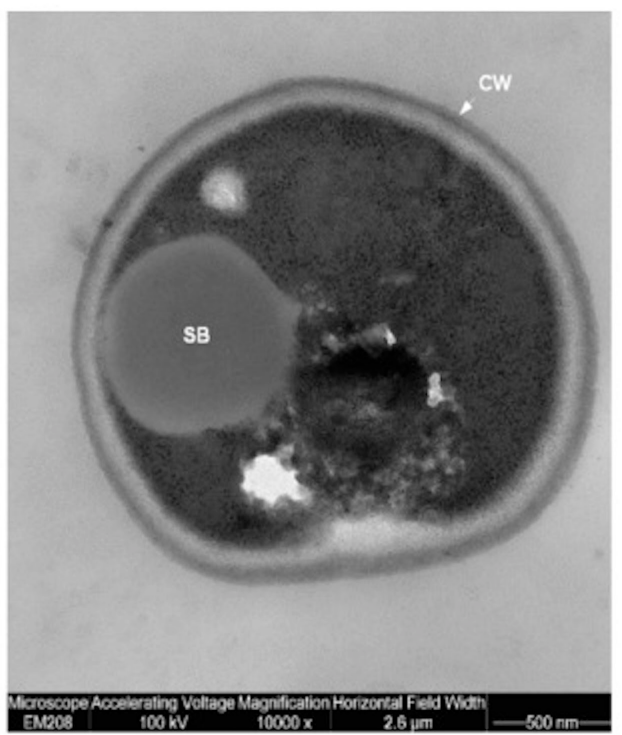

B

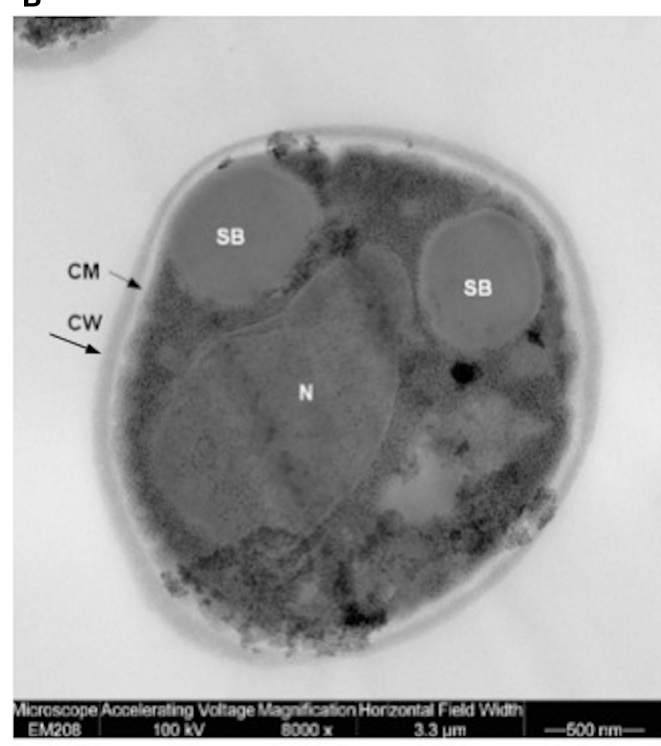

D

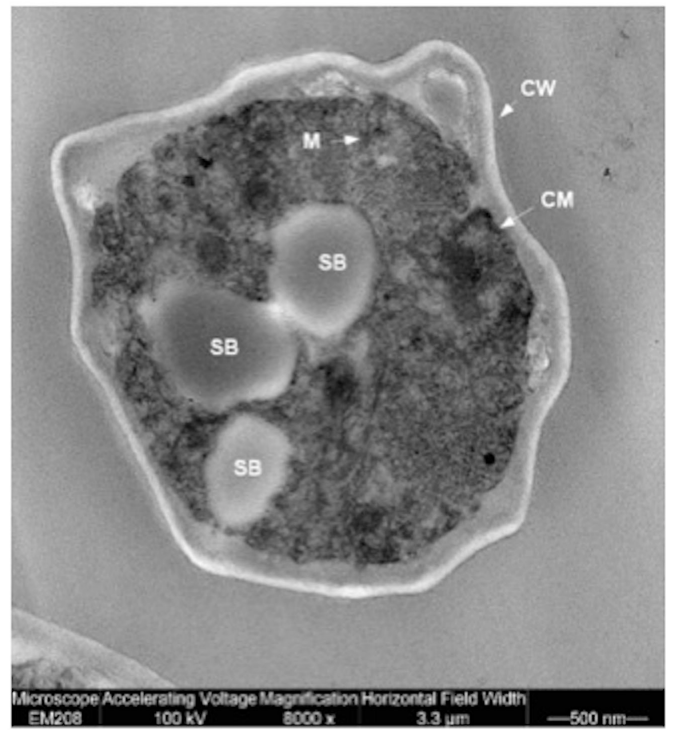

FIGURE 4 | Trasmission electron microscopy (TEM) of aged (4 weeks old) translocants compared to the wild type (WT) strain: (A) WT San1, (B) TNT10, (C) TNT 10/ P53, and (D) TNT 10/H273. N, nucleus; SB, spherical body; CW, cell wall; CM, cell membrane; M, mitochondria; ER, endoplasmic reticulum.

sudden fall of bendability and a specular increase of curvature correspond exactly to the breakpoint. Similarly, NUP145 shows high bendability, high GC content, and low curvature from the $5^{\prime}$ end until the breakpoint (Figures 5D-F). Then, after this, dramatic changes occur and the curvature suddenly increases. Therefore, the comparison of the DNA complexity in TNTs and in the translocant NUP98-TOP2B (Figures $\mathbf{5 G}, \mathbf{H}$ ) may predict the point of junction between the two chromosomes. Peaks of high GC content are usually associated with high thermostability and low homologous recombination (60) while fast re-associating DNA shows low complexity. High GC content, which correlates with high local bending, means also a denser, less flexible DNA and easy B-Z DNA transition. Analysis of computationally predicted physicochemical structural properties of NUP98 showed that bulky changes occur around the breakpoint (Figure 6). In the profile of TIDD (37), the intensity of destabilizations increase of $80 \%$ around the breakpoint (in particular the number of TIDD events rise from 1,500 to 6,000, Figures 6 F) and a similar trend could be observed in the predicted DNA thermodynamic stability with a $60 \%$ change (from -150 to $-115 \mathrm{kcal} / \mathrm{mol}$ ), in the $\mathrm{B}$ to $\mathrm{Z}$ transitions (from 1,270 to $1,450 \mathrm{~kJ} / \mathrm{mol}$ ) and in the $\mathrm{B}$ to $\mathrm{A}$ transitions (from 300 to $-160 \mathrm{~kJ} / \mathrm{mol}$ ) with over $70 \%$ variations around the breakpoint (Figures 6E,A,B respectively). These results clearly and conjointly indicate an overall "weakening" 


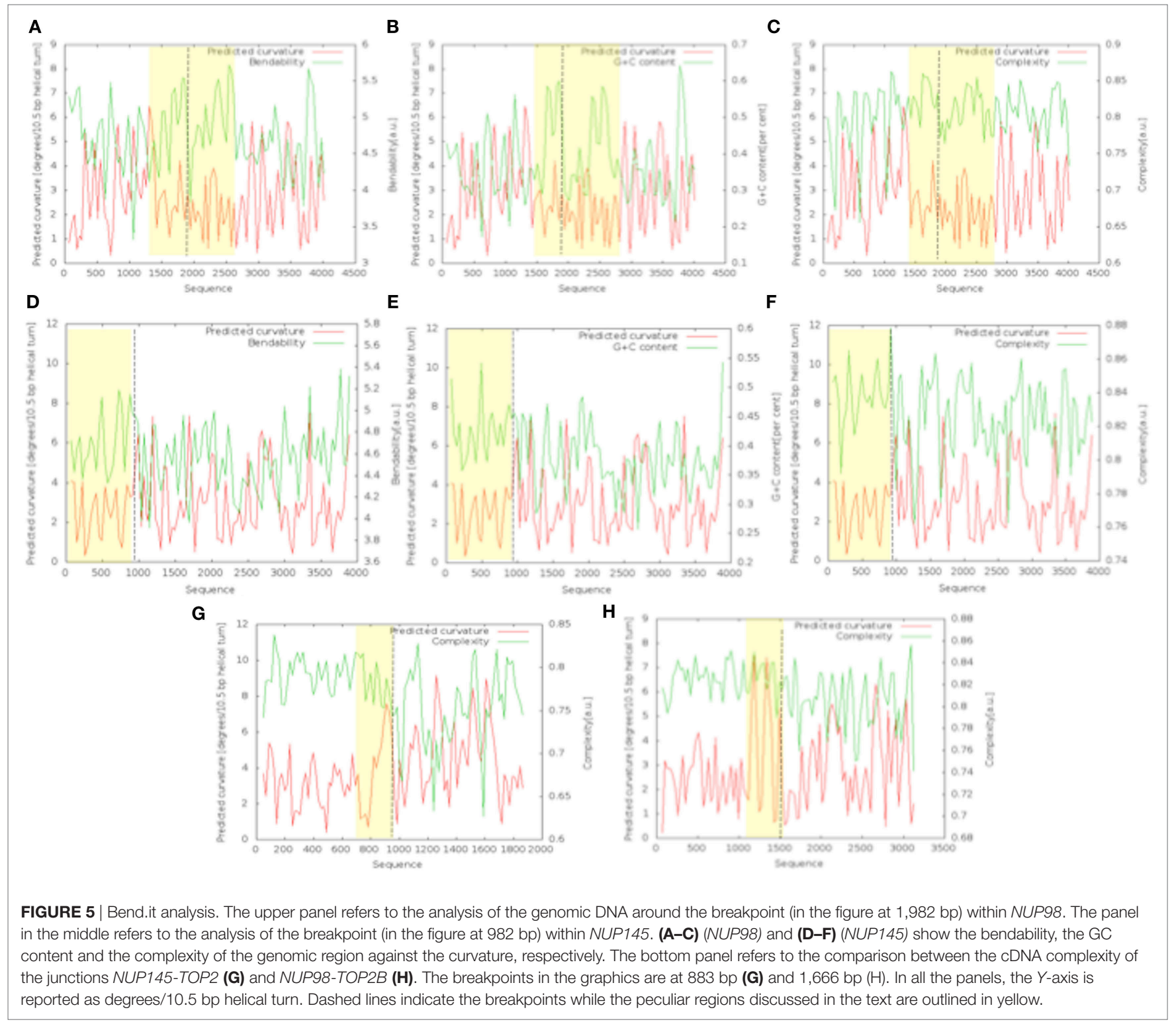

of this genomic region. Conversely, NUP145 did not display pronounced physicochemical changes around the homologous region of the artificially induced breakpoint except with predicted $\mathrm{B}$ to A transition (Figure 6A). However, conformational properties such as the helical repeats and the persistence length have a similar trend either within NUP98 or NUP145 (Figures 6C,D). In both genes, the persistence length increased from 475 to 490-500 nm while helical repeats decreased from approximately $10.52 \mathrm{bp} /$ turn to $10.44-10.46 \mathrm{bp} /$ turn immediately before the breakpoint (Figures 6C,D).

\section{Study of the Effect of Human P53 Expression in TNTs}

In AML, the frequency of P53 mutations ranges from 4 to $15 \%$ (61) and it is, therefore, very low if compared with other types of cancer, such as the high-grade serous carcinoma of the ovary, where P53 mutation rates are close to $100 \%$. Nevertheless, poor prognosis is usually associated with P53 mutations in hematopoietic malignancies and in particular in myeloid leukemia (61). Recently, by using next-generation sequencing, frequent mutations of P53, NOTCH1 and ATM have been identified in chronic lymphocytic leukemia (62). The P53 protein is usually mutated in the hotspot region of the DNA binding domain (aa 273-280) and in particular in the position H273. The high frequency (around 95\%) of this mutation was also confirmed by a leukemic specific profile from a comprehensive analysis of 268 mutations of P53 in 254 patients (63). Many abnormalities of the P53 network have been implicated in the pathogenesis of AML (64) and, moreover, the activity of nucleoporins (in particular Nup98) and both topoisomerases can be modulated by P53 (65-67). The observation that increased expression of P53 

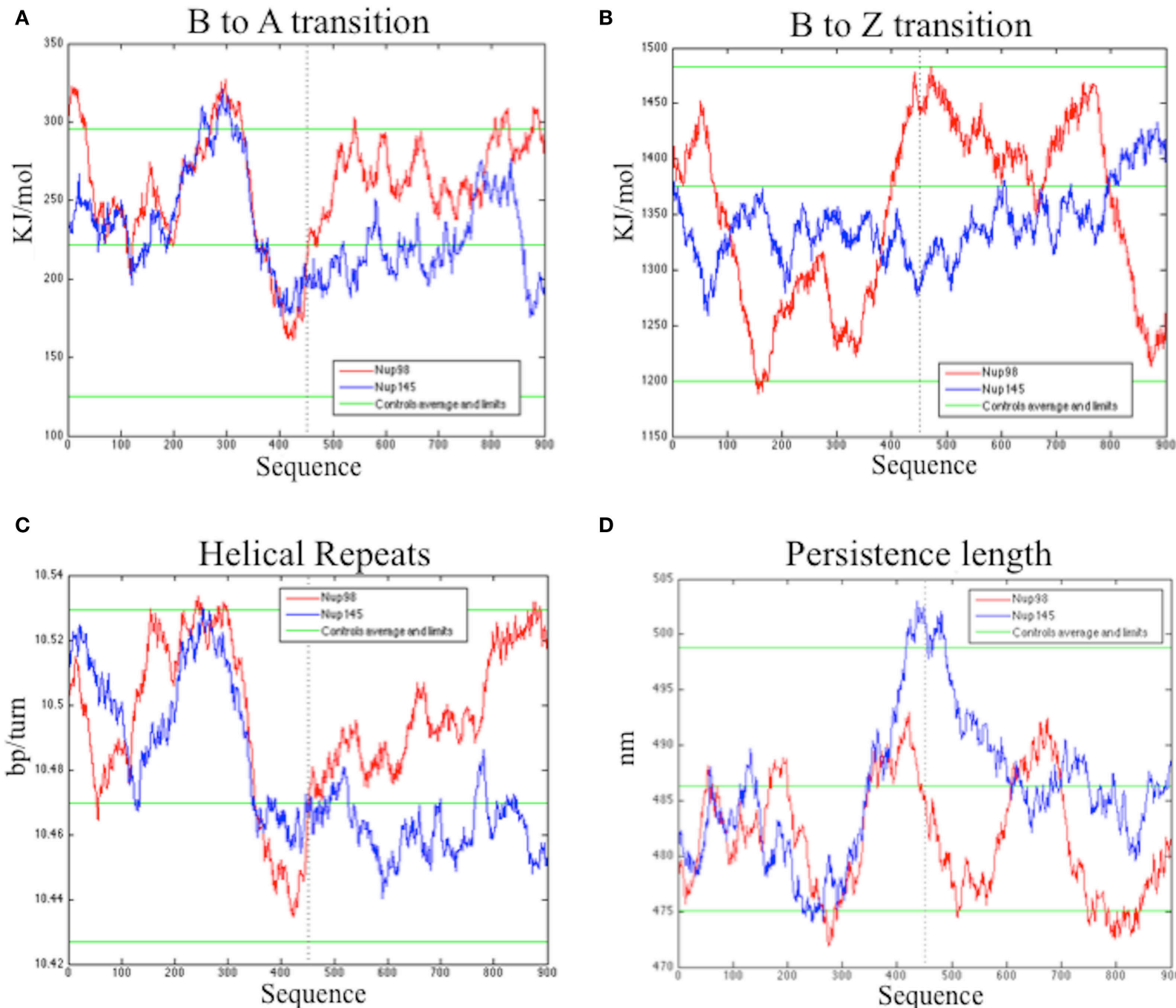

D
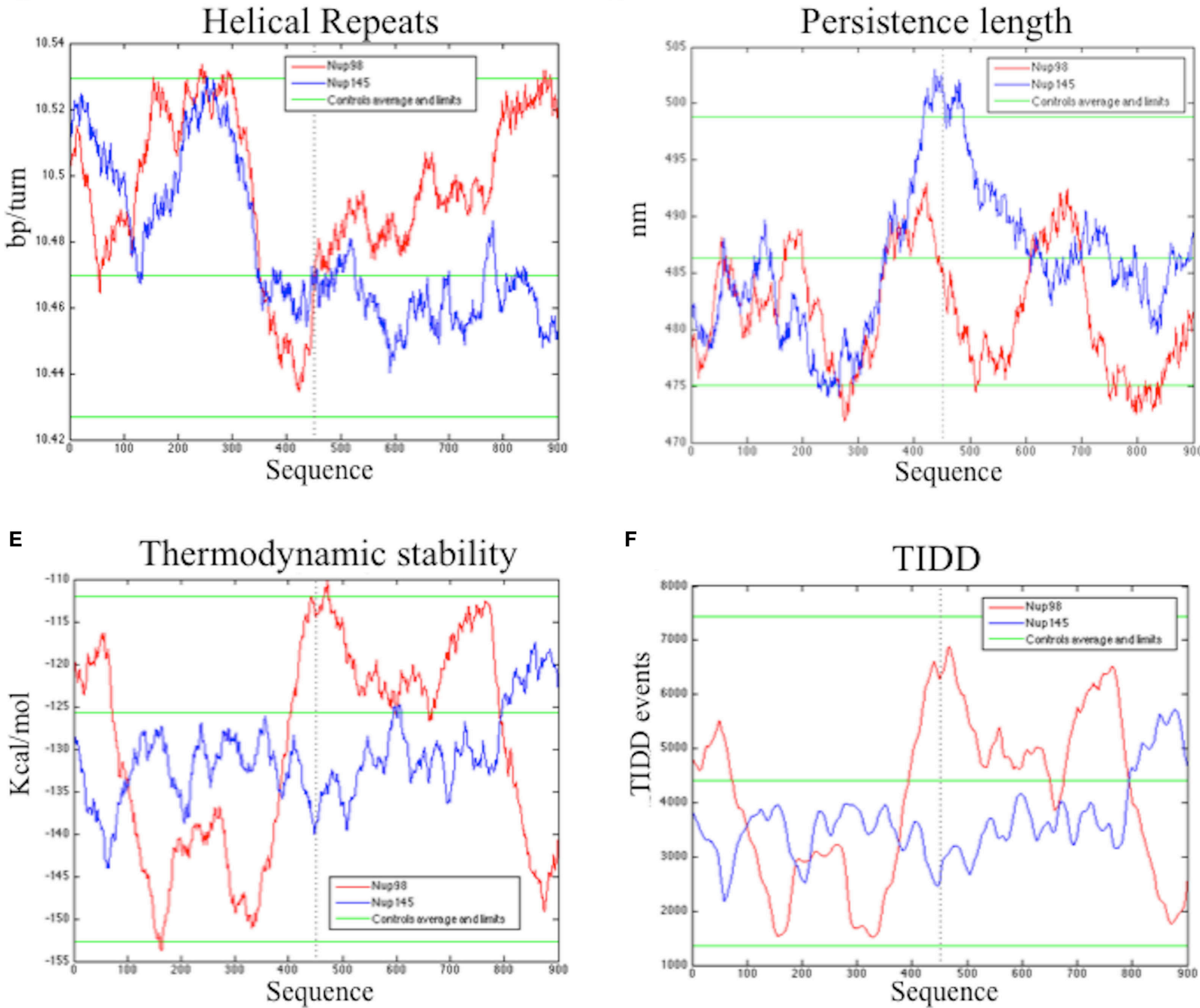

FIGURE 6 | Bioinformatic analysis of the physicochemical and conformational properties of the sequences around the breakpoints of NUP98 (red color) and NUP145 loci (blue color). The three green lines in each graphic correspond to an average, maximum and minimum value of five control sequences (see Materials and Methods for details). (A) B to A transition, (B) B to Z transition, (C) Helical repeats, (D) Persistence length, (E) Thermodynamic stability, (F) thermally induced duplex destabilization (TIDD). The $X$-axis is labeled with numbers representing the nucleotide sequence; the $Y$-axis is labeled, in the different panels, with kiloJoule per mole ( $\mathrm{kJ} / \mathrm{mol})$, nanometers $(\mathrm{nm})$, kilocalories per mole (kcal/mol), base pairs per helical turn (bp/turn). 
protein can be present in several types of human leukemia cells at different stages of differentiation, and in particular in AML (levels 10- to 100-fold those of fresh normal low-density human bone marrow cells), was reported a long time ago (21). More recently, other authors demonstrated that high levels of P53 protein carry an adverse prognosis, regardless of mutation status (22). More than half of patients with AML showed P53 protein expression by flow cytometry (68), P53 increased quantification in $256 \mathrm{AML}$ patients was shown in proteomic profiling (69). Furthermore, it was assessed (24) that strong P53 expression in bone marrow progenitor cells was significantly associated with higher AML risk $(P=0.0006)$ and shorter survival $(P=0.00175)$ rendering P53 as the stronger predictor of transformation to AML (25). A P53 ortholog seems not to be present, or at least has never been identified, in S. cerevisiae. However, the P53 pathway is very well conserved in yeast. Moreover, $S$. cerevisiae has proven to be an efficient model system for studies of the tumor suppressor P53 and in particular of its transcriptional activity (70), apoptosis induction (71) and modulation of the Warburg effect $(18,72)$ that are important prognosis predictors in leukemia (73). We, therefore, transformed the translocant yeast with a constitutive plasmid carrying human P53. The cDNA of P53 and of P53/H273 were cloned without the untranslated regions (UTRs), which may impair translation in yeast (23), in the constitutive vector pJL49 (see Materials and Methods). After the resultant constructs were sequenced TNTs were transformed with the pJL49 + P53 and pJL + P53/H273 constructs and also with an empty pJL49 vector to generate a negative control strain. We verified that P53 did not have any revertant effect on the TNTs phenotype since the SBs were clearly visible also when P53 was expressed in the translocants (Figure 4C). Moreover, since it is known that P53 participates in the regulation of clathrin-mediated endocytosis (74) and since we demonstrated in the past that BIT translocants usually show impaired endocytosis (34), we tested endocytosis in TNTs with and without P53 expression. P53 did not strongly modify the endocytosis in TNTs (Figure 7A), although it seemed to slightly improve it. These results correlate with an increased vitality of the P53-expressing translocants, as suggested by the fluorescent $F U N-1$ assay on the cylindrical intra-vacuolar structures (Figure 7B). In effect, when TNT cells were transformed with P53 they showed a strong staining of the vacuole, similarly to the WT strain, indicating a vigorous and unexpected fitness (Figure 7B). To corroborate this hypothesis, we verified that the constitutive expression of P53 favored the growth of the translocants albeit impairing the proliferation of the WT strain (Figure 8A). All BIT translocants usually grow less and at a lower density than the WT strains from which they derive (46), frequently showing endocytosis defects (34) and short chromosomal life span (47). It was already known that induced overexpression of human P53 inhibits wild yeast proliferation probably because of its transcriptional activity on selective yeast genes involved in cell cycle arrest or cell death $(23,75,76)$. Besides, it was demonstrated that Nup98 regulates the expression of $\mathrm{P} 53$ target genes in mammalian cells (77). Each NUP98 fusion differs from the others with respect to P53 expression. For example, it is known that in case of NUP98 fused with HOXD13, JARID1A, and HOXA9, the HOXA cluster genes are upregulated (5) and that HOX5 under expression limits
P53 expression in tumors (78). Moreover, the complete loss of one or both alleles of P53 can accelerate the development of AML in a NUP98-HOXD13 mouse model (79). On the contrary, topoisomerase II interacts directly with the C-terminal region of P53 (80), although we presently ignore how this interaction can be affected in the NUP98-TOP2 translocation.

For these reasons, we compared the expression of putative P53 targets in TNTs translocants with and without P53 expression. We decided to quantify the expression of six yeast genes that code for proteins directly interacting with P53 like the autophagy-related Atg17 (81) and the chromatin remodeling Rtf1 (82) or that are orthologs of human regulators of P53 such as Sir2 (83), Pak1/ Prk1 (84), Mtbp/Boil (85), and the cyclin-dependent kinase Cdc28 (86). The majority of these genes were similarly expressed in the translocants with and without P53 expression (Figure 8B); nevertheless, a substantial increase (1.79-folds) of the CDC28 transcript was detectable in P53-expressing translocants (Figure 8B). To verify whether this increase was a peculiarity of the translocants, we measured the CDC28 expression in the WT strain transformed with P53. Also in this case, an increase of 1.8folds of CDC28 expression was detected (Figure 8C) suggesting that the effect of P53 on CDC28 is independent on the NUP-TOP translocation effect. The expression of P53 and of the mutant P53/ H273 was verified in two different TNT strains. The two genes were expressed at comparable level in both TNTs and in the WT strain (Figure 8D).

\section{DISCUSSION}

The nucleoporin Nup98 is an essential component of the nuclear pore complex (NPC) and takes part into the nuclear-cytoplasmic traffic, including mRNA export. Several chromosomal rearrangements such as translocations and inversions, with 28 consequent Nup98 gene fusions, are associated with a wide array of hematopoietic malignancies (5). Because in the past we developed the BIT system to generate ad hoc translocations without strain preengineering, just by exploiting the strong homologous recombination of yeast cells $(11,87)$, we decided to reproduce in S. cerevisiae a deeply characterized translocation in humans, responsible of AML, between NUP98 and TOP2B (13). This modeling of the translocation event allowed us to investigate the genetic etiology of AML that can be affected by the physico-chemical properties of the genomic regions around the breakpoints and by the so-called position effect (88) or position-effect variegation (89). Before triggering the translocation between the yeast orthologs NUP145 and TOP2, we investigated the DNA conformational properties around the NUP145 breakpoint, comparing them with those of NUP98 (Figure 5; Figure S5 in Supplementary Material). It is presently not known why the genomic sequences of NUP98 are so prone to break, but it has been postulated that introns act as recombination enhancers within coding sequences, increasing the efficiency of selection at nearby sites. Hotspots can be the results of an antagonistic co-evolution between distinct, but tightly linked, DSB inducers and DSB-cut regions (90). It is well known that many of the translocation breakpoints are within a region of predicted non-B DNA conformation. Cruciforms, triplexes, hairpins, slipped conformations, quadruplexes, and left-handed 
A
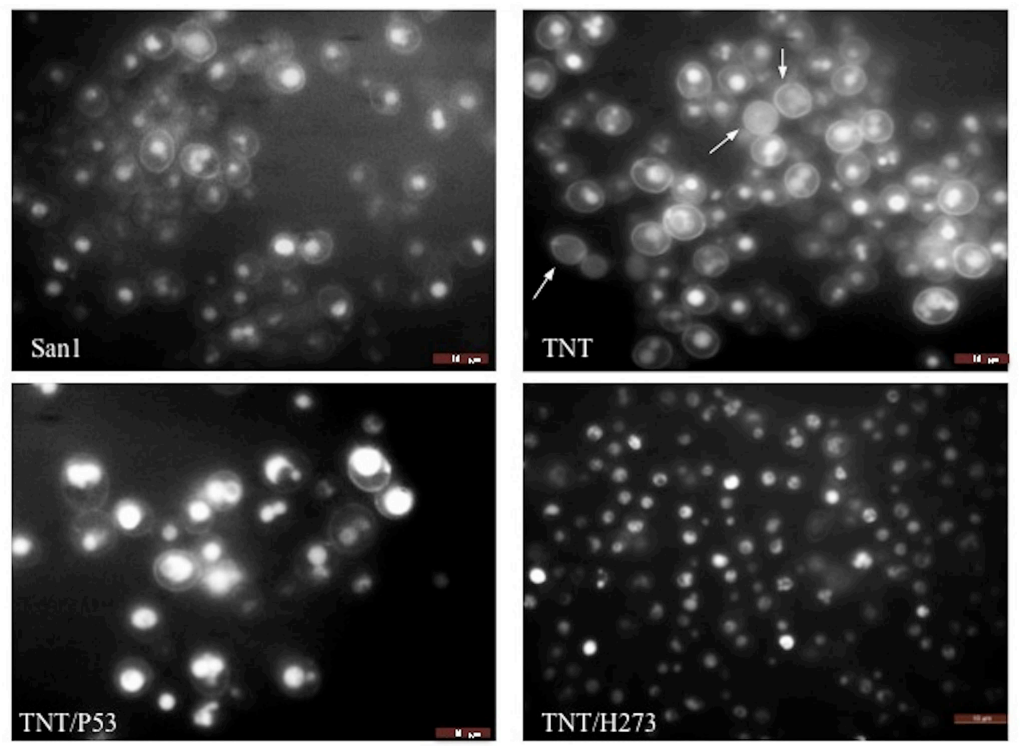

B
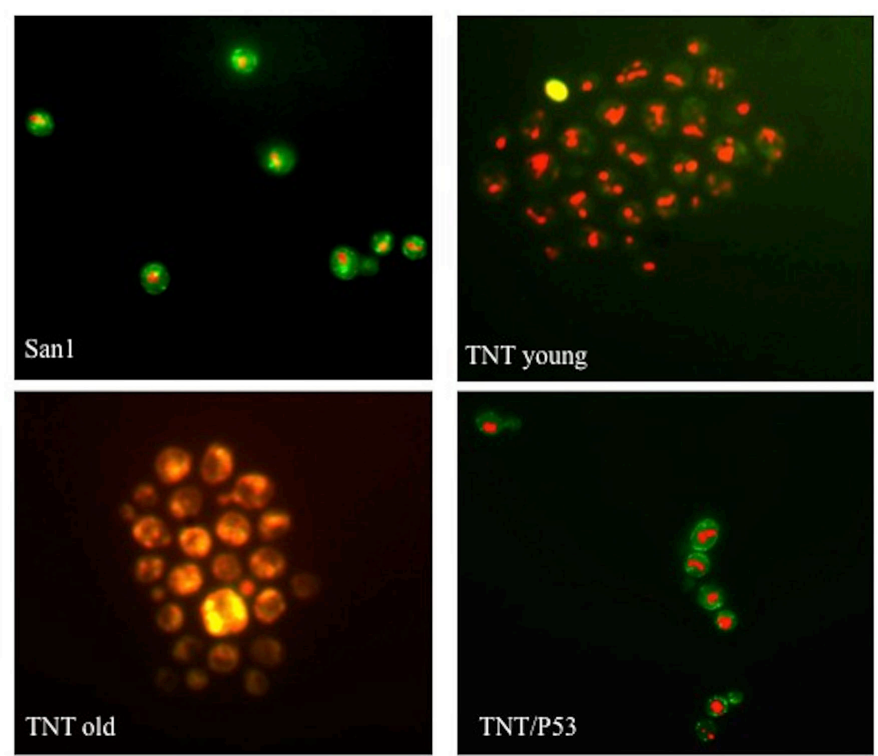

FIGURE 7 | Fluorescent microscopy of (A) endocytosis (B) and cell viability. In (A), lucifer yellow (LY) was used to test endocytosis in the wild type (WT) San1, in TNT cells, in TNTs transformed with P53 (TNT/P53) and with P53 mutated in H273 (TNT/H273). LY gives a high background staining of the cell wall of the translocants with a defective accumulation of the fluorescent molecule in the vacuole. The white arrows indicate cells with almost complete loss of endocytosis (roughly 10\% of the cells). P53 restores a good level of endocytosis in the translocants. In (B), the FUN-1 staining reveals comparable viability of both San1 and the TNT cells transformed with P53. The TNT cells without P53 appeared already suffering when young cultures ( 2 days old) and very sick when old cultures ( 3 weeks old). The dead cells are stained in yellow. After 4 weeks, $5 \%$ of the cells appeared dead (yellow) and all them appeared as very sick (orange color).

Z-DNA are formed by repeats in these regions and are usually responsible for genomic instability leading to translocations, inversions, deletions, or insertions [for an extensive review, see Ref. (91)]. The bendability is a local parameter representing the ability of DNA to bend (usually toward the major groove) as a result of thermal fluctuations (41) or DNA-protein interactions such as the one with P53 (92). Bended segments are usually associated with active transcription and play a role in chromatin organization by influencing nucleosome positioning (93). Comparable features of high bending and very low curvature before a breakpoint can be detected in both NUP145 and NUP98. These results are in agreement with preliminary observations indicating that high bending is a sign of genome integrity (94). In our analysis, a strong bending drop as well as an $80 \%$ increase of TIDD events between bent segments can both predict the exact breakpoint (Figures 5 and 6). These data agree with the typical straight conformation of other fragile sites that are characterized by poor thermal stability and are flanked either side by highly bent DNA 


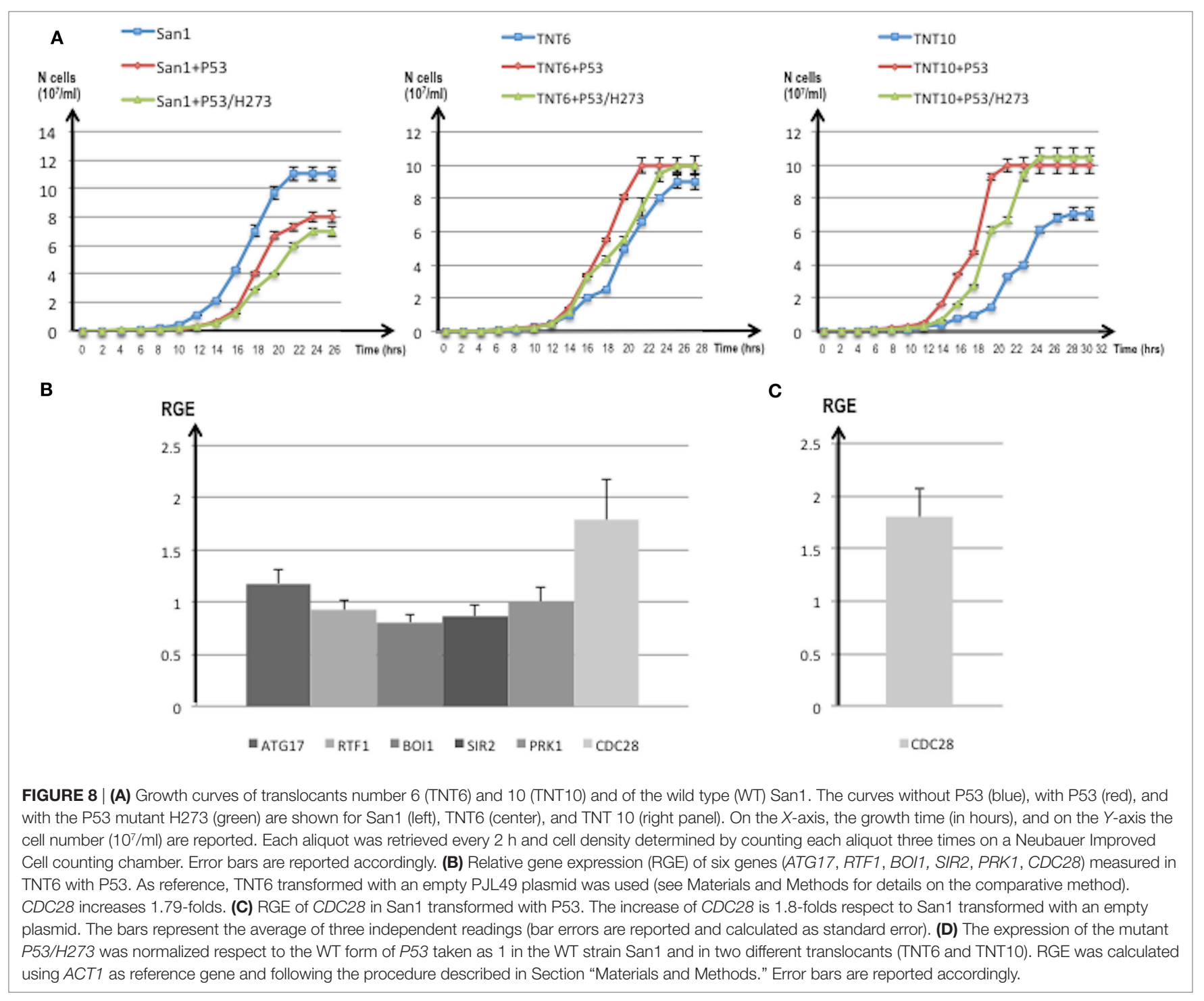

segments (95). Bending strongly affects recombination, especially site-specific recombination $(96,97)$, and, resulting as Z-DNA formation (98), it can thus affect BIT efficiency. BIT has usually a frequency varying from 4 to $10 \%$ using homologies of $65 \mathrm{nt}$ (11). Its frequency variability depends primarily on the genomic sites chosen as targets. It is much easier to target inter-genic regions, promoters, terminators, pre-telomeric sequences $(17,19)$ and vice versa it is difficult to target intragenic or GC rich regions (Tosato and Noel, personal communication). Usually, coding regions correlate not only with low recombination rates but also with weak nucleosome positioning and strong DNA complexity patterns (99) that were in fact detected at the 5'end of NUP145 (Figures 5G). The nup-top translocation represents in this sense an exception because using a standard BIT cassette, with $65 \mathrm{nt}$ of homology and no repeats, the translocation frequency was high (8.3\%; Table S2 in Supplementary Material) despite the targeting of intragenic regions with high GC content (Figure 5). In particular, the locus top 2 seemed to be the hotspot for recombination
(Table S2 in Supplementary Material). The initial difficulty to find a stable TNT $(0.6 \%)$ was, therefore, due to the artificial repeated region added to the cassette for the POP-OUT induction and not to the poor recombinogenicity of the genomic targets, as also testified by the strong intra-recombination of $5^{\prime}$ end NUP145 segments leading to the concatemer. We, thus, demonstrated in this work that it is feasible, although with low frequency, to obtain a perfect fusion in vivo, without any DNA sequence scar, between two selected genomic loci exploiting BIT followed by a selectable POP-OUT of the marker.

When P53 was expressed in the NUP-TOP translocant yeast, BIT was still possible even if with lower frequency, but there was a different distribution of integration events. With a constitutive expression of P53, ectopic integrations (obtained regardless of the homology) more than doubled (Table S2 in Supplementary Material). It is well documented that P53 suppresses homologous recombination and modulates the recombination pathways $(100,101)$, giving an explanation to 
the high rate of ectopic integrants that were found when P53 is expressed (Table S2 in Supplementary Material). P53 seems, moreover, to be less toxic for BIT translocants than for the WT (Figure 7) and its presence is almost beneficial for the translocants, increasing their vitality (Figure 8A). The toxicity of $\mathrm{P} 53$ in yeast is mainly related to gene repression of thioredoxin (Trx1/2), a highly conserved multifunctional anti-oxidative and anti-apoptotic protein family required for the detoxification of reactive oxygen species (ROS) (23). P53 protects against metabolic stress by upregulation of oxidative phosphorylation and modulation of antioxidants (102) and, when expressed in yeast, induces ROS accumulation, which represents the major cause of cell death (23). We previously demonstrated that BIT translocants have a very high deregulated oxidative stress response network resulting in extremely high and persistent ROS levels (47) and that BIT may induce adaptation with improved phenotypic fitness with respect to stressful conditions (46). We, therefore, speculate that all the ROS-related toxic effects of P53 could be negligible in adapted translocant cells. This theory is supported by our findings on the CDC28 gene that is overexpressed in TNTs/P53. The increase in the levels of CDC28 expression is present in cells that are able to re-enter the cell cycle more efficiently after stress (103). In order to verify whether the stress in our cells was given by the expression of $P 53$ or by the translocation event per se, we measured the level of expression of CDC28 in the WT overexpressing P53. The overexpression was the same in the WT and in the translocants suggesting that the constitutive expression of P53 is generally stressful for the yeast cell, independently of the translocation event and that P53 does not further worsen the stressful condition of the translocants. On the other hand, we noticed that the expression of human P53 did not considerably affect the vitality (and the transformability) of the WT yeast strain subjected to BIT transformation (Table S2 in Supplementary Material). We know from previous studies that heat shock, required for DNA uptake, induces a transient G1 arrest in yeast cells for a period of approximately $1 \mathrm{~h}$ (104), and that once the heat shock proteins are induced and thermo-tolerance is acquired, the normal cell cycle resumes (105). Normal cell cycle progression in yeast relies on activation of the cyclin-dependent kinase Cdc28 and plasmid-driven overexpression of CDC28 can suppress delay on cell cycle progression observed upon stress (103). Therefore, we can postulate that the long-lasting induction of CDC28 by $\mathrm{P} 53$ is beneficial for stressed cells to recover after heat shock to reenter the cell cycle more efficiently after DNA transformation.

Finally, neither P53 nor its H273-mutant was able to rescue the unusual phenotype typical of the aged translocants. SBs started to appear in TNTs as interspersed cytoplasmic aggregates, without any membrane, after 3 weeks of continuous growth. In budding yeast, as in higher eukaryotes, processing bodies (P-bodies) are dynamic foci within the cytoplasm that are not solid aggregates, as the stress granules, but liquid-like droplets (106) containing untranslating mRNAs and proteins involved in mRNA decay (107). Their size depends on the extension of defects in mRNA decapping and, more generally, to environmental perturbations (108). However, in the case of cellular stress, the size usually varies from 0.1 to $0.3 \mu \mathrm{m}^{2}$ (106) that is comparable with the size of the
SBs observed within the aged TNTs (Figure 4). Recently, it has been demonstrated that the C. elegans germ P-granules, which share a lot of similarities with P-bodies, associate with Nup98 and need an intact Nup98 for integrity and function (109). We still do not know whether the Nup98 ortholog, Nup145, is as well important for P-bodies in yeast, but our study indicates a role of this nucleoporin outside the nucleus and related to RNA-rich bodies within the cytoplasm. Nup98 is already known to be a tumor suppressor because it stabilizes P53 target genes (77). Here, we propose that its oncogenic properties could also involve dysregulation of RNA turnover in the cytoplasm supporting the hypothesis that P-body disassembly and subsequent mRNA deregulation might be linked to certain types of cancers (110). However, notwithstanding many studies, the exact mechanism by which P-bodies impact the development and progression of cancer is largely unknown and a thorough understanding of their roles in carcinogenesis could help in the identification of new targets for cancer therapy (111).

\section{CONCLUSION}

Our data suggest that Nup98 could be related to P-bodies regulation in yeast and, therefore, be responsible for mRNA turnover in the cytoplasm. We suppose that other leukemic translocations involving Nup98 might be characterized by the same defects of cytoplasmic mRNA dysregulation. We confirmed that, like NUP98 in humans, NUP145 is haploinsufficient in yeast. It is likely that this NUP-TOP induced translocation generates secondary chromosomal rearrangements as we demonstrated in the past for other BIT events (17) and as shown by the Southern hybridizations of the translocated clones (Figure S3 in Supplementary Material). Possibly, secondary aneuploidies resulting from NUP145 haploinsufficiency could generate genome instability, as already surmised for NUP98 translocations in human cells (5). Last, but certainly not least, this work points out a role of $P 53$ in these Nup98-translocated cells, although the inactivation of $P 53$ is a frequent event in tumorigenesis $(61,71)$. Here, we demonstrated that in the yeast model expression of P53 improved vitality, endocytosis and growth of translocated cells, fostering considerations on its possible role in translocationrelated tumors.

\section{AUTHOR CONTRIBUTIONS}

VT and DN had the idea and conceived the strategies; VT designed and performed the majority of the experiments; NW helped in the PCRs and microscopy; JZ performed the bioinformatics analysis; GS and RM contributed to the P53 data; VT, MB, and $\mathrm{CB}$ analyzed the data and wrote the paper.

\section{ACKNOWLEDGMENTS}

The Authors wish to thank Claudio Gamboz (Transmission Electron Microscopy Service, University of Trieste) for technical help and Alberto Inga (CIBIO, Trento) for fruitful suggestions. A particular thank to Jean-Luc Parrou (Toulouse, France) for having provided the plasmid pJL49. 


\section{FUNDING}

This work was supported by FWF project P26713 (to MB). JZ was a Post-Doctoral fellow supported by the Slovenian Research Agency (ARRS, Ljubljana).

\section{REFERENCES}

1. Kabachinski G, Schwartz TU. The nuclear pore complex-structure and function at a glance. J Cell Sci (2015) 128:423-9. doi:10.1242/jcs.083246

2. Mossaid I, Fahrenkrog B. Complex commingling: nucleoporins and the spindle assembly checkpoint. Cells (2015) 4:706-25. doi:10.3390/cells4040706

3. Ptak C, Wozniak RW. Nucleoporins and chromatin metabolism. Curr Opin Cell Biol (2016) 40:153-60. doi:10.1016/j.ceb.2016.03.024

4. Takeda A, Yaseen NR. Nucleoporins and nucleocytoplasmic transport in hematologic malignancies. Semin Cancer Biol (2014) 27:3-10. doi:10.1016/j. semcancer.2014.02.009

5. Gough SM, Slape CI, Aplan PD. NUP98 gene fusions and hematopoietic malignancies: common themes and new biologic insights. Blood (2011) 118:6247-57. doi:10.1182/blood-2011-07-328880

6. Lin YW, Slape C, Zhang Z, Aplan PD. NUP98-HOXD13 transgenic mice develop a highly penetrant, severe myelodysplastic syndrome that progresses to acuteleukemia. Blood(2005) 106:287-95. doi:10.1182/blood-2004-12-4794

7. Kroon E, Thorsteinsdottir U, Mayotte N, Nakamura T, Sauvageau G. NUP98-HOXA9 expression in hemopoietic stem cells induces chronic and acute myeloid leukemias in mice. EMBO J (2001) 20:350-61. doi:10.1093/ emboj/20.3.350

8. Qiu JJ, Zeisig BB, Li S, Liu W, Chu H, Song Y, et al. Critical role of retinoid/ rexinoid signaling in mediating transformation and therapeutic response of NUP98-RARG leukemia. Leukemia (2015) 29:1153-62. doi:10.1038/ leu.2014.334

9. Takeda A, Goolsby C, Yaseen NR. NUP98-HOXA9 induces long-term proliferation and blocks differentiation of primary human CD34+ hematopoietic cells. Cancer Res (2006) 66:6628-37. doi:10.1158/0008-5472.CAN-060458

10. Fahrenkrog B, Martinelli V, Nilles N, Fruhmann G, Chatel G, Juge S, et al. Expression of leukemia-associated Nup98 fusion proteins generates an aberrant nuclear envelope phenotype. PLoS One (2016) 11:e0152321. doi:10.1371/journal.pone.0152321

11. Tosato V, Waghmare S, Bruschi CV. Non-reciprocal chromosomal bridge-induced translocation (BIT) by targeted DNA integration in yeast. Chromosoma (2005) 114:15-27. doi:10.1007/s00412-005-0332-x

12. Nikitin D, Tosato V, Zavec AB, Bruschi CV. Cellular and molecular effects of non-reciprocal chromosome translocation in S. cerevisiae. Proc Natl Acad Sci U S A (2008) 105:9703-8. doi:10.1073/pnas.0800464105

13. Nebral K, Schmidt HH, Haas OA, Strehl S. NUP98 is fused to topoisomerase (DNA) IIbeta $180 \mathrm{kDa}$ (TOP2B) in a patient with acute myeloid leukemia with a new t(3;11)(p24;p15). Clin Cancer Res (2005) 11:6489-94. doi:10.1158/1078-0432.CCR-05-0150

14. Prébet T, Jean E, Autret A, Charbonnier A, Rey J, Etienne A, et al. Combination of cytarabine and topotecan in patients treated for acute myeloid leukemia with persistent disease after frontline induction. Leuk Lymphoma (2012) 53:2186-91. doi:10.3109/10428194.2012.685733

15. Slape C, Aplan PD. The role of NUP98 gene fusions in hematologic malignancy. Leuk Lymphoma (2004) 45:1341-50. doi:10.1080/104281903100016 59325

16. Kobzev YN, Martinez-Climent J, Lee S, Chen J, Rowley JD. Analysis of translocations that involve the NUP98 gene in patients with $11 \mathrm{p} 15$ chromosomal rearrangements. Genes Chromosomes Cancer (2004) 41:339-52. doi:10.1002/ gcc. 20092

17. Rossi B, Noel P, Bruschi CV. Different aneuploidies arise from the same bridge-induced chromosomal translocation event in Saccharomyces cerevisiae. Genetics (2010) 186:775-90. doi:10.1534/genetics.110.120683

18. Tosato V, Grüning NM, Breitenbach M, Arnak R, Ralser M, Bruschi CV. Genomic instability and Warburg effect: two yeast models for cancer cells. Front Oncol (2013) 2:212. doi:10.3389/fonc.2012.00212

\section{SUPPLEMENTARY MATERIAL}

The Supplementary Material for this article can be found online at http://journal.frontiersin.org/article/10.3389/fonc.2017.00231/ full\#supplementary-material.

19. Tosato V, Sidari S, Bruschi CV. Bridge-induced chromosome translocation in yeast relies upon a Rad54/Rdh54-dependent, Pol32-independent pathway. PLoS One (2013) 8:e60926. doi:10.1371/journal.pone.0060926

20. Koníková E, Kusenda J. P53 protein expression in human leukemia and lymphoma cells. Neoplasma (2001) 48:290-8.

21. Koeffler HP, Miller C, Nicolson MA, Raynard J, Bosselman RA. Increased expression of P53 in human leukemia cells. Proc Natl Acad Sci U S A (1986) 83:4035-9. doi:10.1073/pnas.83.11.4035

22. Kornblau SM, Barnett J, Qiu Y, Chen W, Faderl S, Coombs KR, et al. P53 protein expression levels are prognostic in AML and predict for mutational status. Blood (2007) 110:2397.

23. Hadj Amor IY, Smaoui K, Chaabène I, Mabrouk I, Djemal L, Elleuch H, et al. Human p53 induces cell death and downregulates thioredoxin expression in Saccharomyces cerevisiae. FEMS Yeast Res (2008) 8:1254-62. doi:10.1111/j.1567-1364.2008.00445.x

24. Saft L, Karimi M, Ghaderi M, Matolcdy A, Mufti GJ, Kulasekararaj A, et al. P53 protein expression independently predicts outcome in patients with lower risk myelodisplastic syndromes with del(5q). Haematologica (2014) 99:104-9. doi:10.3324/haematol.2013.098103

25. Nagy EE, Finna C, Demian S, Chira L, Horvath E. P53 protein as a survival biomarker in myelodysplastic syndromes: immunohistochemical morphometric study. Farmacia (2016) 64:104-11.

26. Bruschi CV, Howe GA. High frequency FLP-independent homologous DNA recombination of $2 \mathrm{mu}$ plasmid in the yeast Saccharomyces cerevisiae. Curr Genet (1988) 14:191-9. doi:10.1007/BF00376739

27. Cheng TH, Chang CR, Joy P, Yablok S, Gartenberg MR. Controlling gene expression in yeast by inducible site-specific recombination. Nucleic Acids Res (2000) 28:E108. doi:10.1093/nar/28.24.e108

28. Akada R, Kitagawa T, Kaneko S, Toyonaga D, Ito S, Kakihara Y, et al. PCRmediated seamless gene deletion and marker recycling in Saccharomyces cerevisiae. Yeast (2006) 23:399-405. doi:10.1002/yea.1365

29. Delneri D, Gardner DC, Bruschi CV, Oliver SG. Disruption of seven hypothetical aryl alcohol dehydrogenase genes from Saccharomyces cerevisiae and construction of a multiple knock-out strain. Yeast (1999) 15:1681-9. doi:10.1002/ (SICI)1097-0061(199911)15:15<1681::AID-YEA486>3.0.CO;2-A

30. Wach A, Brachat A, Pohlmann R, Philippsen P. New heterologous modules for classical or PCR-based gene disruptions in Saccharomyces cerevisiae. Yeast (1994) 10:1793-808. doi:10.1002/yea.320101310

31. Teste MA, Duquenne M, François JM, Parrou JL. Validation of reference genes for quantitative expression analysis by real-time RT-PCR in S. cerevisiae. BMC Mol Biol (2009) 10:99. doi:10.1186/1471-2199-10-99

32. Schmittgen TD, Livak KJ. Analyzing real-time PCR data by the comparative C(T) method. Nat Protoc (2008) 3:1101-8. doi:10.1038/nprot.2008.73

33. Riezman H. Endocytosis in yeast: several of the yeast secretory mutants are defective in endocytosis. Cell (1985) 40:1001-9. doi:10.1016/00928674(85)90360-5

34. Nikitin DV, Bruschi CV, Sims J, Breitenbach M, Rinnerthaler M, Tosato V. Chromosome translocation may lead to PRK1-dependent anticancer drug resistance in yeast via endocytic actin network deregulation. Eur J Cell Biol (2014) 93:145-56. doi:10.1016/j.ejcb.2014.03.003

35. Rybak P, Kwiatek J, Pierzynska-Mach A, Zawrotniak M, Dobricki J. Paradoxical Pattern of RNA Staining with Pyronin Y in Live and Intact Cells The Role of Fluorescence Quenching and Photobleaching. Konstanz, Germany: FOM (2011). p. 2-A.

36. SantaLucia J Jr. A unified view of polymer, dumbbell, and oligonucleotide DNA nearest-neighbor thermodynamics. Proc Natl Acad Sci U S A (1998) 95:1460-5. doi:10.1073/pnas.95.4.1460

37. Zrimec J, Lapanje A. Fast prediction of DNA melting bubbles using DNA thermodynamic stability. IEEE/ACM Trans Comput Biol Bioinform (2015) 12:1137-45. doi:10.1109/TCBB.2015.2396057 
38. Lisser L, Margalit H. Determination of common structural features in E. coli promoters by computer analysis. Eur J Biochem (1994) 223:823-30. doi:10.1 111/j.1432-1033.1994.tb19058.x

39. Vlahovicek K, Kaján L, Pongor S. DNA analysis servers: plot.it, bend. it, model.it and IS. Nucleic Acids Res (2003) 31:3686-7. doi:10.1093/nar/ gkg559

40. Gabrielian A, Bolshoy A. Sequence complexity and DNA curvature. Comput Chem (1999) 23:263-74. doi:10.1016/S0097-8485(99)00007-8

41. Goodsell GD, Dickerson RE. Bending and curvature calculations in B-DNA. Nucleic Acids Res (1994) 22:5497-503. doi:10.1093/nar/22.24.5497

42. Geggier S, Kotlyar A, Vologodskii A. Temperature dependence of DNA persistence length. Nucleic Acids Res (2011) 39:1419-26. doi:10.1093/nar/ gkq932

43. Thomsen MC, Nielsen M. Seq2Logo: a method for construction and visualization of amino acid binding motifs and sequence profiles including sequence weighting, pseudo counts and two-sided representation of amino acid enrichment and depletion. Nucleic Acids Res (2012) 40:W281-7. doi:10.1093/nar/gks469

44. Chakravarty A, Carlson JM, Khetani RS, Gross RH. A novel ensemble learning method for de novo computational identification of DNA binding sites. BMC Bioinformatics (2007) 8:249. doi:10.1186/1471-2105-8-249

45. Nitiss JL. DNA topoisomerase II and its growing repertoire of biological functions. Nat Rev Cancer (2009) 9:327-37. doi:10.1038/nrc2608

46. Tosato V, Sims J, West N, Colombin M, Bruschi CV. Post-translocational adaptation drives evolution through genetic selection and transcriptional shift in S. cerevisiae. Curr Genet (2017) 63:281-92. doi:10.1007/s00294-016-0635-x

47. Sims J, Bruschi CV, Bertin C, Breitenbach M, Schroeder S, Eisenberg T, et al. Extreme oxidative stress levels are detected at the end of the chronological life span of translocant yeast. Mol Genet Genomics (2016) 291:423-35. doi:10.1007/s00438-015-1120-9

48. Freeman JA. Origin of auer bodies. Blood (1966) 27:499-510.

49. Lui J, Castelli LM, Pizzinga M, Simpson CE, Hoyle NP, Bailey KL, et al. Granules harboring translationally active mRNAs provide a platform for P-body formation following stress. Cell Rep (2014) 9:944-54. doi:10.1016/j. celrep.2014.09.040

50. Deutschbauer AM, Jaramillo DF, Proctor M, Kumm J, Hillenmeyer ME, Davis RW, et al. Mechanisms of haploinsufficiency revealed by genome-wide profiling in yeast. Genetics (2005) 169:1915-25. doi:10.1534/genetics.104.036871

51. Teixeira MT, Siniossoglou S, Podtelejnikov S, Benichou JC, Mann M, Dujon B, et al. Two functionally distinct domains generated by in vivo cleavage of Nup145p: a novel biogenesis pathway for nucleoporins. EMBO J (1997) 16:5086-97. doi:10.1093/emboj/16.16.5086

52. Wente SR, Blobel G. NUP145 encodes a novel yeast glycine-leucine-phenylalanine-glycine (GLFG) nucleoporin required for nuclear envelope structure. J Cell Biol (1994) 125:955-69. doi:10.1083/jcb.125.5.955

53. Emtage JL, Bucci M, Watkins JL, Wente SR. Defining the essential functional regions of the nucleoporin Nup145p. J Cell Sci (1997) 110:911-25.

54. Carlson JM, Chakravarty A, DeZiel CE, Gross RH. SCOPE: a web server for practical de novo motif discovery. Nucleic Acids Res (2007) 35:W259-64. doi:10.1093/nar/gkm310

55. Fan WH, Woelfle MA, Mosig G. Two copies of a DNA element, 'Wendy', in the chloroplast chromosome of Chlamydomonas reinhardtii between rearranged gene clusters. Plant Mol Biol (1995) 29:63-80. doi:10.1007/BF00019119

56. Lobachev KS, Rattray A, Narayanan V. Hairpin- and cruciform-mediated chromosome breakage: causes and consequences in eukaryotic cells. Front Biosci (2007) 12:4208-20. doi:10.2741/2381

57. Kouzine F, Levens D. Supercoil-driven DNA structures regulate genetic transactions. Front Biosci (2007) 12:4409-23. doi:10.2741/2398

58. Lieber MR, Lu H, Gu J, Schwarz K. Flexibility in the order of action and in the enzymology of the nuclease, polymerases, and ligase of vertebrate non-homologous DNA end joining: relevance to cancer, aging, and the immune system. Cell Res (2008) 18:125-33. doi:10.1038/cr.2007.108

59. Gonçalves MA, van Nierop GP, Holkers M, de Vries AA. Concerted nicking of donor and chromosomal acceptor DNA promotes homology-directed gene targeting in human cells. Nucleic Acids Res (2012) 40:3443-55. doi:10.1093/ nar/gkr1234

60. Gruss A, Moretto V, Ehrlich SD, Duwat P, Dabert P. GC-rich DNA sequences block homologous recombination in vitro. J Biol Chem (1991) 266:6667-9.
61. Melo MB, Ahmad NN, Lima CS, Pagnano KB, Bordin S, Lorand-Metze I, et al. Mutations in the p53 gene in acute myeloid leukemia patients correlate with poor prognosis. Hematology (2002) 7:13-9. doi:10.1080/10245330290020090

62. Athanasakis E, Melloni E, Rigolin GM, Agnoletto C, Voltan R, Vozzi D, et al. The 53 transcriptional pathway is preserved in ATM mutated and NOTCH1 mutated chronic lymphocytic leukemias. Oncotarget (2014) 5:12635-45. doi:10.18632/oncotarget.2211

63. Zenz T, Vollmer D, Trbusek M, Smardova J, Benner A, Soussi T, et al. TP53 mutation profile in chronic lymphocytic leukemia: evidence for a disease specific profile from a comprehensive analysis of 268 mutations. Leukemia (2010) 24:2072-9. doi:10.1038/leu.2010.208

64. Wojcik I, Szybka M, Golanska E, Rieske P, Blonski JZ, Robak T, et al. Abnormalities of the P53, MDM2, BCL2 and BAX genes in acute leukemias. Neoplasma (2005) 52:318-24.

65. Yarbrough ML, White MA, Fontoura BMA. Shaping the p53 response with nucleoporins. Mol Cell (2012) 48:665-6. doi:10.1016/j.molcel.2012.11.027

66. Yeo CQX, Alexander I, Lin Z, Lim S, Anig OA, Kumar R, et al. P53 maintains genomic stability by preventing interference between transcription and replication. Cell Rep (2016) 15:132-46. doi:10.1016/j.celrep.2016.03.011

67. Gobert C, Bracco L, Rossi F, Olivier M, Tazi J, Lavelle F, et al. Modulation of DNA topoisomerase I activity by p53. Biochemistry (1996) 35:5778-86. doi: $10.1021 /$ bi952327w

68. Cavalcanti GB, Vasconcelos FC, Pinto de Faria G, Scheiner MA, de Almeida Dobbin J, Klumb CE, et al. Coexpression of p53 protein and MDR functional phenotype in leukemias: the predominant association in chronic myeloid leukemia. Cytometry B Clin Cytom (2004) 61:1-8. doi:10.1002/cyto.b.20013

69. Kornbalu SM, Tibes R, Qiu YH, Chen W, Kantarjian HM, Andreeff M, et al. Functional proteomic profiling of AML predicts response and survival. Blood (2009) 113:154-64. doi:10.1182/blood-2007-10-119438

70. Leão M, Gomes S, Soares J, Bessa C, Maciel C, Ciribilli Y, et al. Novel simplified yeast-based assays of regulators of p53-MDMX interaction and p53 transcriptional activity. FEBS J (2013) 280:6498-507. doi:10.1111/febs.12552

71. Guaragnella N, Palermo V, Galli A, Moro L, Mazzoni C, Giannattasio S. The expanding role of yeast in cancer research and diagnosis: insights into the function of the oncosuppressors p53 and BRCA1/2. FEMS Yeast Res (2014) 14:2-16. doi:10.1111/1567-1364.12094

72. Diaz-Ruiz R, Rigoulet M, Devin A. The Warburg and Crabtree effects: on the origin of cancer cell energy metabolism and of yeast glucose repression. Biochim Biophys Acta (2011) 1807:568-76. doi:10.1016/j.bbabio.2010. 08.010

73. Hong M, Xia Y, Zhu Y, Zhao H-H, Zhu H, Xie Y, et al. TP53-induced glycolysis and apoptosis regulator protects from spontaneous apoptosis and predicts poor prognosis in chronic lymphocytic leukemia. Leuk Res (2016) 50:72-7. doi:10.1016/j.leukres.2016.09.013

74. Endo Y, Sugiyama A, Li SA, Ohmori K, Ohata H, Yoshida Y, et al. Regulation of clathrin-mediated endocytosis by p53. Genes Cells (2008) 13:375-86. doi:10.1111/j.1365-2443.2008.01172.x

75. Coutinho I, Pereira G, Leão M, Gonçalves J, Côrte-Real M, Saraiva L. Differential regulation of p53 function by protein kinase $\mathrm{C}$ isoforms revealed by a yeast cell system. FEBS Lett (2009) 583:3582-8. doi:10.1016/j. febslet.2009.10.030

76. Nigro JM, Sikorski R, Reed SI, Vogelstein B. Human p53 and CDC2Hs genes combine to inhibit the proliferation of Saccharomyces cerevisiae. Mol Cell Biol (1992) 12:1357-65. doi:10.1128/MCB.12.3.1357

77. Singer S, Zhao R, Barsotti AM, Ouwehand A, Fazollahi M, Coutavas E, et al. Nuclear pore component Nup98 is a potential tumor suppressor and regulates posttranscriptional expression of select p53 target genes. Mol Cell (2012) 48:799-810. doi:10.1016/j.molcel.2012.09.020

78. Raman V, Martensen SA, Reisman D, Evron E, Odenwald WF, Jaffee E, et al. Compromised HOXA5 function can limit p53 expression in human breast tumors. Nature (2000) 405:974-8. doi:10.1038/35016125

79. Xu H, Menendez S, Schlegelberger B, Bae N, Aplan PD, Göhring G, et al. Loss of p53 accelerates the complications of myelodysplastic syndrome in a NUP98-HOXD13-driven mouse model. Blood (2012) 120:3089-97. doi:10.1182/blood-2012-01-405332

80. Cowell IG, Okorokov AL, Cutts SA, Padget K, Bell M, Milner J, et al. Human topoisomerase II $\alpha$ and II $\beta$ interact with the C-terminal region of P53. Exp Cell Res (2000) 225:86-94. doi:10.1006/excr.1999.4772 
81. Morselli E, Shen S, Ruckenstuhl C, Bauer MA, Mariño G, Galluzzi L, et al. p53 inhibits autophagy by interacting with the human ortholog of yeast Atg17, RB1CC1/FIP200. Cell Cycle (2011) 10:2763-9. doi:10.4161/cc.10.16.16868

82. Koerte A, Cong T, Li X, Wahane K, Cai M. Suppression of the yeast mutation rft1-1 by human p53. J Biol Chem (1995) 270:22556-64. doi:10.1074/ jbc. 270.38 .22556

83. Smith J. Human Sir2 and the "silencing" of p53 activity. Trends Cell Biol (2002) 12:404-6. doi:10.1016/S0962-8924(02)02342-5

84. Thiagalingam S, Kinzler KW, Vogelstein B. PAK1, a gene that can regulate p53 activity in yeast. Proc Natl Acad Sci US A (1995) 92:6062-6. doi:10.1073/ pnas.92.13.6062

85. Boyd MT, Vlatkovic N, Haines DS. A novel cellular protein (MTBP) binds to MDM2 and induces a G1 arrest that is suppressed by MDM2. J Biol Chem (2000) 275:31883-90. doi:10.1074/jbc.M004252200

86. Hixon ML, Flores AI, Wagner MW, Gualberto A. Ectopic expression of cdc2/ cdc28 kinase subunit Homo sapiens 1 uncouples cyclin B metabolism from the mitotic spindle cell cycle checkpoint. Mol Cell Biol (1998) 18:6224-37. doi:10.1128/MCB.18.11.6224

87. Tosato V, Nicolini C, Bruschi CV. DNA bridging of yeast chromosomes VIII leads to near-reciprocal translocation and loss of heterozygosity with minor cellular defects. Chromosoma (2009) 118:179-91. doi:10.1007/ s00412-008-0187-z

88. Kleinjan DJ, van Heyningen V. Position effect in human genetic disease. Hum Mol Genet (1998) 7:1611-8. doi:10.1093/hmg/7.10.1611

89. Elgin SCR, Reuter G. Position-effect variegation, heterochromatin formation, and gene silencing in Drosophila. Cold Spring Harb Perspect Biol (2013) 5:a017780. doi: $10.1101 /$ cshperspect.a017780

90. Friberg U, Rice WR. Cut Thy neighbor: cyclic birth and death of recombination hotspots via genetic conflict. Genetics (2008) 179:2229-38. doi:10.1534/ genetics.107.085563

91. Bacolla A, Wells RD. Non-B DNA conformations as determinants of mutagenesis and human disease. Mol Carcinog (2009) 48:273-85. doi:10.1002/ mc. 20507

92. Pan Y, Nussinov R. p53-Induced DNA bending: the interplay between p53-DNA and p53-p53 interactions. JPhys Chem (2008) 112:6716-24. doi: $10.1021 /$ jp800680w

93. Drew HR, Travers AA. DNA bending and its relation to nucleosome positioning. J Mol Biol (1985) 186:773-90. doi:10.1016/0022-2836(85)90396-1

94. Gonzalez-Huici V, Szakal B, Urulangodi M, Psakhye I, Castellucci F, Menolfi D, et al. DNA bending facilitates the error-free DNA damage tolerance pathway and upholds genome integrity. EMBO J (2014) 33:327-40. doi:10.1002/embj.201387425

95. Palin AH, Critcher R, Fitzgerald DJ, Anderson JN, Farr CJ. Direct cloning and analysis of DNA sequences from a region of the Chinese hamster genome associated with aphidicolin-sensitive fragility. J Cell Sci (1998) 111:1623-34.

96. Snyder UK, Thompson JF, Landy A. Phasing of protein-induced DNA bends in a recombination complex. Nature (1989) 341:255-7. doi:10.1038/ $341255 \mathrm{a} 0$

97. Luetke KH, Sadowski PD. The role of DNA bending in Flp-mediated site-specific recombination. J Mol Biol (1995) 251:493-506. doi:10.1006/ jmbi.1995.0451

98. Arican E, Ekimler S, Tosato V, Bruschi CV. Characterization of bridge induced translocation (Bit) driven by Z-DNA formation in Saccharomyces cerevisiae via non-B DB and SIDD/Z-DNA web-based servers. Fresen Environ Bull (2016) 25:1365-71.

99. Bolshoy A, Shapiro K, Trifonov EN, Ioshikhes I. Enhancement of the nucleosomal pattern in sequences of lower complexity. Nucleic Acids Res (1997) 25:3248-54. doi:10.1093/nar/25.16.3248

100. Romanova LY, Willers H, Blagosklonny MV, Powell SN. The interaction of p53 with replication protein A mediates suppression of homologous recombination. Oncogene (2004) 23:9025-33. doi:10.1038/sj.onc.1207982

101. Linke SP, Sengupta S, Khabie N, Jeffries BA, Buchhop S, Miska S, et al. p53 interacts with hRAD51 and hRAD54, and directly modulates homologous recombination. Cancer Res (2003) 63:2596-605.

102. Sinthupibulyakit C, Ittarat W, St Clair WH, St Clair DK. p53 protects lung cancer cells against metabolic stress. Int J Oncol (2010) 37:1575-81. doi:10.3892/ijo_00000811

103. Nadal-Ribelles M, Solé C, Xu Z, Steinmetz LM, de Nadal E, Posas F. Control of Cdc28 CDK1 by a stress-induced lncRNA. Mol Cell (2014) 53:549-61. doi:10.1016/j.molcel.2014.01.006

104. Shin DY, Matsumoto K, Iida H, Uno I, Ishikawa T. Heat shock response of Saccharomyces cerevisiae mutants altered in cyclic AMP-dependent protein phosphorylation. Mol Cell Biol (1987) 7:244-50. doi:10.1128/MCB.7.1.244

105. Mendenhall MD, Hodge AE. Regulation of Cdc28 cyclin-dependent protein kinase activity during the cell cycle of the yeast Saccharomyces cerevisiae. Microbiol Mol Biol Rev (1998) 62:1191-243.

106. Kroschwald S, Maharana S, Mateju D, Malinovska L, Nüske E, Poser I, et al. Promiscuous interactions and protein disaggregases determine the material state of stress-inducible RNP granules. Elife (2015) 4:e06807. doi:10.7554/ eLife.06807

107. Decker CJ, Parker R. P-bodies and stress granules: possible roles in the control of translation and mRNA degradation. Cold Spring Harb Perspect Biol (2012) 4:a012286. doi:10.1101/cshperspect.a012286

108. Nissan T, Parker R. Analyzing P-bodies in Saccharomyces cerevisiae. Methods Enzymol (2008) 448:507-20. doi:10.1016/S0076-6879(08)02625-6

109. Voronina E, Seydoux G. The C. elegans homolog of nucleoporin Nup98 is required for the integrity and function of germline $P$. granules. Development (2010) 137:1441-50. doi:10.1242/dev.047654

110. Cougot N, Daguenet E, Baguet A, Cavalier A, Thomas D, Bellaud P, et al. Overexpression of MLN51 triggers P-body disassembly and formation of a new type of RNA granules. J Cell Sci (2014) 127:4692-701. doi:10.1242/ jcs. 154500

111. Anderson P, Kedersha N, Ivanov P. Stress granules, P-bodies and cancer. Biochim Biophys Acta (2015) 1849:861-70. doi:10.1016/j.bbagrm.2014.11.009

Conflict of Interest Statement: The authors declare that the research was conducted in the absence of any commercial or financial relationship that could be construed as a potential conflict of interest.

Copyright (C) 2017 Tosato, West, Zrimec, Nikitin, Del Sal, Marano, Breitenbach and Bruschi. This is an open-access article distributed under the terms of the Creative Commons Attribution License (CC BY). The use, distribution or reproduction in other forums is permitted, provided the original author(s) or licensor are credited and that the original publication in this journal is cited, in accordance with accepted academic practice. No use, distribution or reproduction is permitted which does not comply with these terms. 